\title{
Stringent response of Escherichia coli: revisiting the bibliome using literature mining
}

\author{
Sónia Carneiro ${ }^{*}$, Anália Lourenço ${ }^{\dagger}$, Eugénio C Ferreira and Isabel Rocha
}

\begin{abstract}
Background: Understanding the mechanisms responsible for cellular responses depends on the systematic collection and analysis of information on the main biological concepts involved. Indeed, the identification of biologically relevant concepts in free text, namely genes, tRNAs, mRNAs, gene products and small molecules, is crucial to capture the structure and functioning of different responses.
\end{abstract}

Results: In this work, we review literature reports on the study of the stringent response in Escherichia coli. Rather than undertaking the development of a highly specialised literature mining approach, we investigate the suitability of concept recognition and statistical analysis of concept occurrence as means to highlight the concepts that are most likely to be biologically engaged during this response. The co-occurrence analysis of core concepts in this stringent response, i.e. the (p)ppGpp nucleotides with gene products was also inspected and suggest that besides the enzymes RelA and SpoT that control the basal levels of (p)ppGpp nucleotides, many other proteins have a key role in this response. Functional enrichment analysis revealed that basic cellular processes such as metabolism, transcriptional and translational regulation are central, but other stress-associated responses might be elicited during the stringent response. In addition, the identification of less annotated concepts revealed that some (p) ppGpp-induced functional activities are still overlooked in most reviews.

Conclusions: In this paper we applied a literature mining approach that offers a more comprehensive analysis of the stringent response in E. coli. The compilation of relevant biological entities to this stress response and the assessment of their functional roles provided a more systematic understanding of this cellular response. Overlooked regulatory entities, such as transcriptional regulators, were found to play a role in this stress response. Moreover, the involvement of other stress-associated concepts demonstrates the complexity of this cellular response.

\section{Background}

Scientific literature represents a valuable source of biological information, in particular on the description of biological entities that we can find in a cellular system and how they are related to each other. To identify references to these entities in texts, here designated as biological concepts, literature mining approaches can be applied. Lately, these approaches have provided for substantial knowledge discovery in diverse biological domains [1-7]. In systems biology, this is of particular interest, since literature-derived evidences can assist in the reconstruction of biochemical and signalling

\footnotetext{
* Correspondence: soniacarneiro@deb.uminho.pt

† Contributed equally

Institute for Biotechnology and Bioengineering (IBB), Centre of Biological Engineering, University of Minho, Campus de Gualtar, 4710-057 Braga, Portugal
}

(c) 2011 Carneiro et al; licensee BioMed Central Ltd. This is an Open Access article distributed under the terms of the Creative Commons Attribution License (http://creativecommons.org/licenses/by/2.0), which permits unrestricted use, distribution, and reproduction in any medium, provided the original work is properly cited.

network models. Taking advantage of information retrieval and extraction methodologies it is possible to cover a multitude of biological entities and many other aspects that characterise these complex biological representations. In this work, literature mining was used to get a deep view on the structure of the stringent response in E. coli, which was then helpful in the mathematical modelling of this stress response [8].

This stress response has been studied in the last four decades, but many of the cellular mechanisms involved are still unclear [9-14]. Studies have shown that the accumulation of unusual guanosine nucleotides, collectively called (p)ppGpp, is the hallmark of the stringent response of $E$. coli [15-18] (Figure 1). Such accumulation is known to be controlled by the activity of two enzymes, the ribosome-bound RelA enzyme (ppGpp synthetase I) that synthesises (p)ppGpp nucleotides 


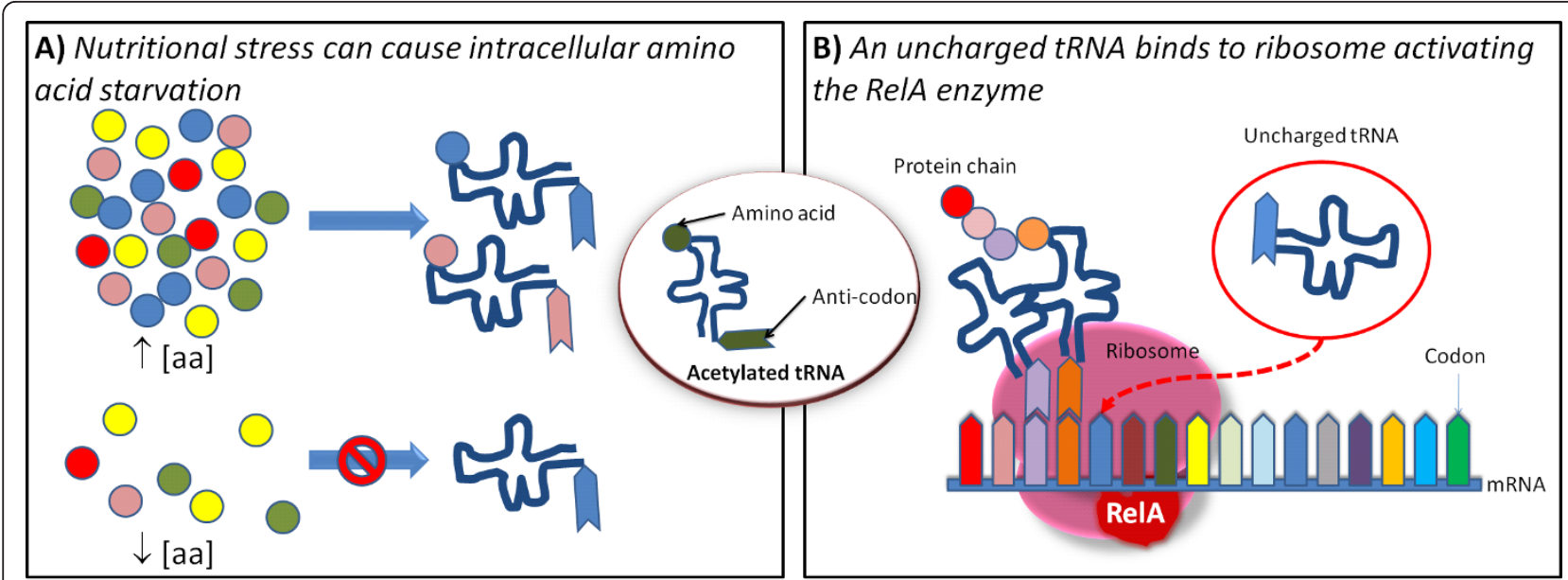

C) The RelA activity is regulated by the ribosomal protein $L 11$

D) (p)ppGpp binds to the RNA polymerase influencing the competition between sigma factors
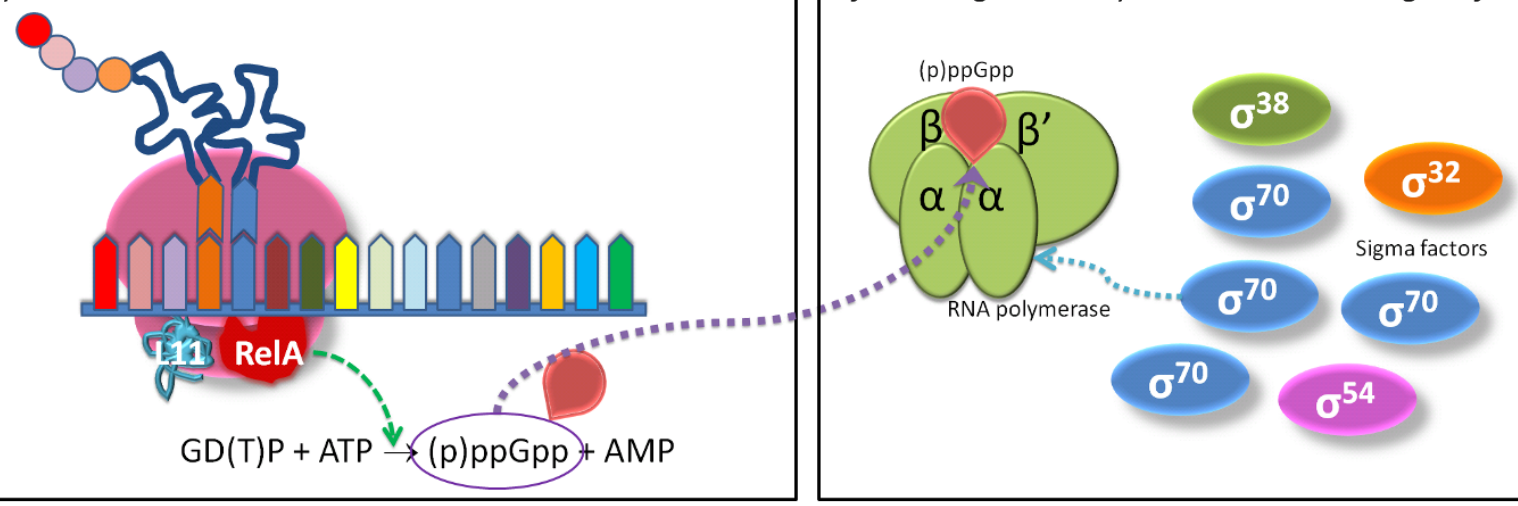

\section{E) DksA augments the (p)ppGpp control of the transcription initiation}

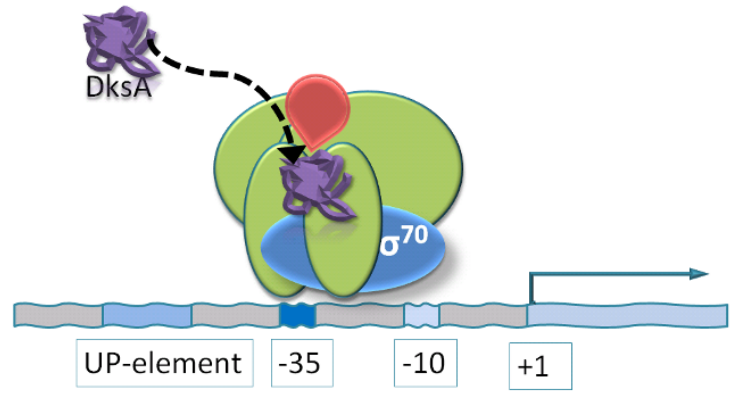

Bacterial promoter architecture
F) Promoter-specific effects of (p)ppGpp on gene expression

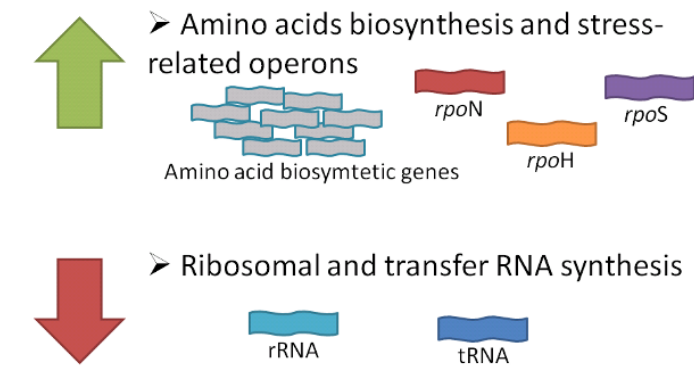

Figure 1 The (p)ppGpp-mediated stringent response. (A) Low amino acid concentrations lead to decreased charging of the corresponding tRNAs. (B) The translational machinery depends on the translocation along the mRNA whereby a new acetylated-tRNA is positioned in the ribosome. Whenever an uncharged tRNA binds to the ribosome, the elongation of the polypeptide chain is stalled. (C) The stringent factor RelA is then activated in the presence of the ribosomal protein L11, catalyzing the synthesis of (p)ppGpp nucleotides. (D) These nucleotides bind directly to the RNA polymerase and affect the binding abilities of sigma factors to the core RNA polymerase. (E) The cofactor DksA also binds to the RNA polymerase and augments the (p)ppGpp regulation of the transcription initiation at certain $\sigma 70$-dependent promoters, functioning both as negative and positive regulators. (F) These regulators change the gene expression: (i) decreasing the transcription activity of genes involved in translational activities; (ii) and increasing the transcription of stress-related operons and genes encoding for enzymes needed for the synthesis and the transport of amino acids. 
upon the depletion of amino acids [19] and the bifunctional SpoT enzyme (ppGpp synthetase II) that is responsible for maintaining the intracellular levels of $(p)$ ppGpp nucleotides via enzymatic degradation [20]. The (p)ppGpp-mediated response involves the control of the genetic expression by direct interaction of the (p)ppGpp nucleotides with the RNA polymerase (RNAP) [21,22], activating the transcription of genes coding for stressassociated sigma factors and amino acid biosynthesis and inhibiting the transcription of stable RNAs (rRNA and tRNA) [23].

This (p)ppGpp-mediated scenario is quite complex and many fundamental details remain uncertain, such as the mechanisms underlying the activation of transcription by (p)ppGpp [24,25] or the global effects of activating/inhibiting certain stress-related genes [26,27]. To be able to systematically identify and collect information on the main components of the stringent response a semiautomatic literature review process was implemented. We propose the application of a literature mining approach that, besides complementing manual literature review, takes advantage of public database information and ontology assignments to provide for large-scale enrichment and contextualisation of textual evidences. The literature mining approach aimed at (i) corroborating existing knowledge about key players and the processes in which they are involved during the stringent response of $E$. coli and (ii) unveiling knowledge that has been overlooked in the up to date reviews.

\section{Results}

The investigation of the stringent response involved the search for three main biological classes: genetic components (genes, RNA and DNA molecules), gene products (proteins, transcription factors and enzymes) and small molecules. These classes cover for most of the relevant biological concepts involved in this response and each biological concept can be associated with one or more variant names. The annotation of these concepts refers to the mark-up of textual contents that match one of those names.

In the applied literature mining approach, full-text documents related to the stringent response of $E$. coli (published till 2009) were retrieved using NCBI PubMed tools and were further processed to automatically identify and annotate biological concepts in the text. Since we were looking for a wide range of biological concepts, the examination of full-texts was expected to bring much more information. Therefore, the search was limited to documents with link to full-texts. From a total of 251 documents, only 193 full-text documents comprise the corpus in this study, due to the availability of links to full text articles in PubMed and institutional journal subscriptions (see Additional file 1). EcoCyc database
[28], a key resource for E. coli studies, provided for most of the controlled vocabulary used for the annotation of relevant entities in the documents, namely genes, gene products and small molecules. Proteomics Standards Initiative-Molecular Interactions (PSI-MI) ontology [29] supported the annotation of experimental techniques. After manual curation, i.e. a process to refine and correct annotations, the corpus consisted of 93893 annotations for 2474 biological concepts that were distributed as follows (see Figure 2): genetic components and small molecules accounted for the largest number of annotations (33\% and 35\% of the overall number of annotations, respectively) and almost half of the biological concepts annotated in full-text documents were classified as genetic components. Additionally, assignments of annotated concepts to MultiFun ontology [30] and Gene Ontology (GO) [31] enabled the identification of biological processes and molecular functions, which were distributed as follows (see Figure 2 ): enzymes and proteins contributed to most GO assignments; and the MultiFun cellular function categories 'Metabolism'(BC-1) and 'Location of gene products' (BC-7) related to most of the annotated genes. Details are given in Additional file 2.

The analysis of the corpus was based on the assumption that relevant entities could be identified by finding frequent concepts in documents. As such, we measured the frequency of concepts $\left(\right.$ freq $\left._{t i}\right)$ and the mean $\left(\right.$ mean $\left._{t i}\right)$ and the standard deviation $\left(s t d_{t i}\right)$ of the annotations to evaluate their relevance in the discussion throughout the corpus. In other words, the concept frequency $\left(\right.$ freq $\left._{t i}\right)$ estimated the fraction of documents where a concept was annotated, while the mean $\left(\operatorname{mean}_{t i}\right)$ and standard deviation $\left(s t d_{t i}\right)$ of concept annotations evaluated the distribution of annotations over the corpus. A concept that shows high frequency in the corpus and is annotated more than once per document is likely to have some relevance in the stringent response. To further attest this assumption, we have estimated the variance-to-mean ratio $\left(V M R_{t i}\right)$ that measures the dispersion of annotations for each concept, indicating the existence of document clusters.

We have additionally estimated the frequency of coannotation $\left(\right.$ freq $\left._{t i, t j}\right)$ of two concepts, i.e. the number of documents in which concepts $t_{i}$ and $t_{j}$ co-occur within the corpus. Co-occurrence analyses has been previously used to establish relationships between biomedical concepts from literature, such as genes and pathways $[2,32]$. Here we expected to identify pairs of concepts that cooccur frequently in documents, assuming that this frequency is an indication of some sort of relationship between the two concepts and related to the stringent response. Further analyses were performed to evaluate concept annotations per decade, which allowed us to 

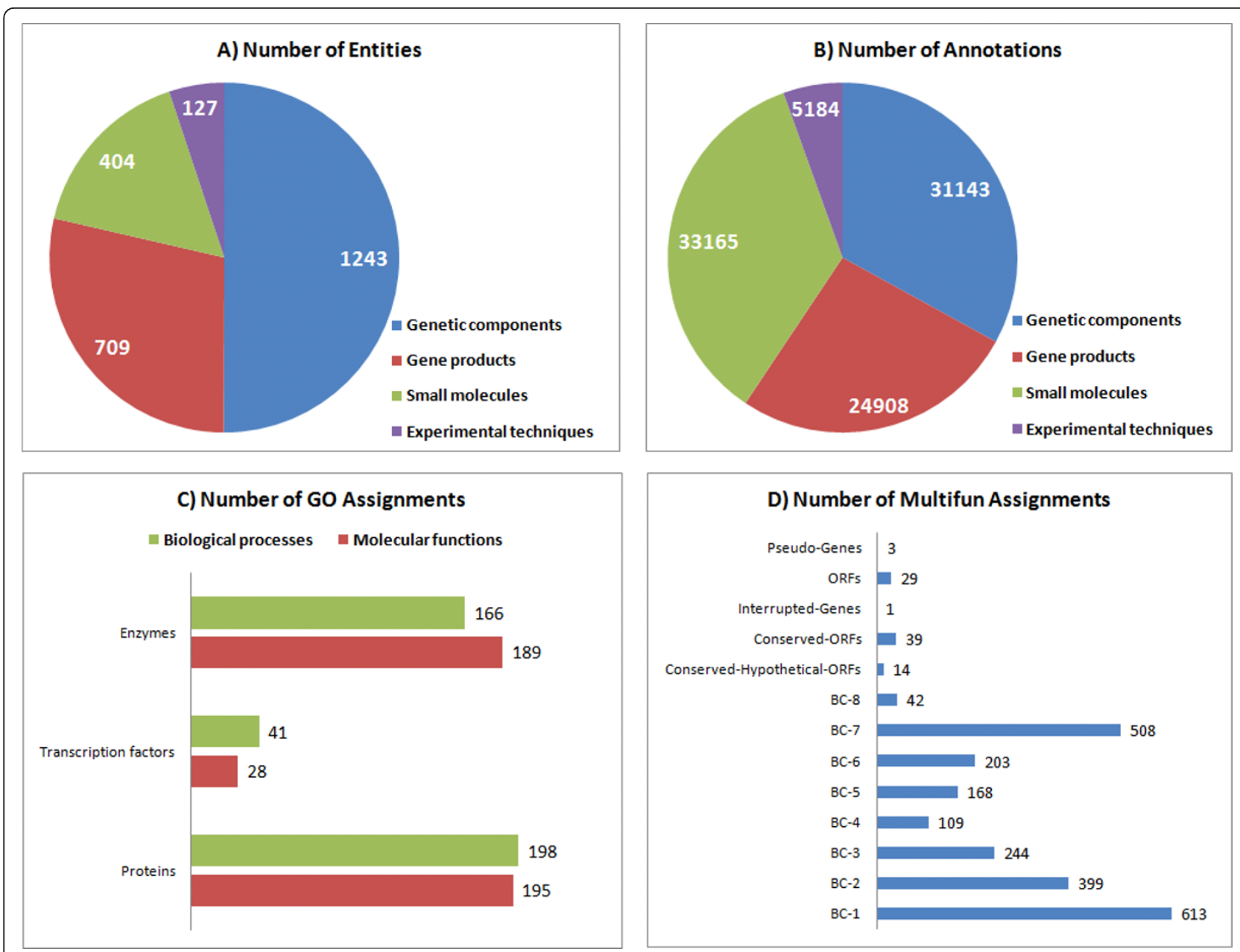

Figure 2 Corpus annotation contents. Overview of the extent of biological concepts (A) and concept annotations (B) per class in the corpus. $\mathrm{GO}$ assignments (C) for molecular functions and biological processes mapped for each set of gene products (i.e. enzymes, transcription factors and other proteins) and MultiFun gene assignments (D) for different functional roles (BC-1 to Metabolism, BC-2 to Information transfer, BC-3 to Regulation, BC-4 to Transport, BC-5 to Cell processes, BC-6 to Cell structure, BC-7 to Location of gene products and BC-8 to Extrachromosomal origin) were recognized in the corpus.

understand the evolving of the topic throughout the years and, in particular, the impact of technology-driven advances. At last, functional enrichment analysis was performed to evaluate which ontology terms were most assigned to annotated concepts. In this analysis we have only considered MultiFun and GO terms related with molecular functions and biological processes, respectively. These results will be detailed in the next subsections.

\section{Biological concepts}

The analysis of the frequency of annotated genetic components (see Table 1) evidenced that entities like the relA gene and the RNA and DNA molecules were annotated in more than $70 \%$ of the documents. Though the representativeness of such entities in these documents was considerably high (i.e. high mean of annotation), the annotations were over-dispersed (VMR > 1). For example, the relA gene has a mean of over 22 annotations per document and a VMR of over 33, meaning that some documents present a very high number of annotations, while others rarely mention that gene. This suggests that only a small part of the documents are focused on the discussion of this gene in the stringent response and those are probably the most relevant considering the characterization of its role in this cellular process.

Similarly, the analysis of gene product annotations (see Table 2) exposed RelA, RNAP and ribosomes as highly annotated entities (present in over than $50 \%$ of the documents) with a considerable degree of over-dispersion $(\mathrm{VMR}>1)$. It was interesting to verify that the Fis transcriptional dual regulator, which modulates several cellular processes, such as the transcription of stable 
Table 1 Annotations of the genetic components in the corpus.

\begin{tabular}{|c|c|c|c|c|c|c|c|}
\hline Class & Concept & Number of Annotations & Number of Documents & $\%$ Frequency (Eq. 1) ${ }^{\psi}$ & Mean (Eq. 2) & Std (Eq. 3) & VMR (Eq. 4) \\
\hline \multirow[t]{19}{*}{ Genes } & relA & 3163 & 138 & 71.50 & 22.92 & 27.23 & 33.14 \\
\hline & spot & 1315 & 88 & 45.60 & 14.94 & 27.42 & 52.07 \\
\hline & lac & 354 & 63 & 32.64 & 5.620 & 19.42 & 72.20 \\
\hline & lacz & 534 & 50 & 25.91 & 10.68 & 17.16 & 28.90 \\
\hline & thi & 91 & 47 & 24.35 & 1.940 & 0.050 & 4.000 \\
\hline & rel & 523 & 47 & 24.35 & 11.13 & 20.68 & 36.36 \\
\hline & recA & 82 & 39 & 20.21 & 2.100 & 1.810 & 0.5000 \\
\hline & $r p s L$ & 95 & 36 & 18.65 & 2.640 & 3.530 & 4.500 \\
\hline & thr & 84 & 36 & 18.65 & 2.330 & 3.760 & 4.500 \\
\hline & $r p s G$ & 103 & 34 & 17.62 & 3.030 & 7.250 & 16.33 \\
\hline & $\overline{l e u}$ & 98 & 34 & 17.62 & 2.880 & 6.800 & 18.00 \\
\hline & rpos & 205 & 33 & 17.10 & 6.210 & 10.83 & 16.67 \\
\hline & kan & 308 & 33 & 17.10 & 9.330 & 16.61 & 28.44 \\
\hline & $g \ln V$ & 42 & 31 & 16.06 & 1.350 & 0.7400 & 0 \\
\hline & rpoB & 389 & 30 & 15.54 & 12.97 & 17.60 & 24.08 \\
\hline & ptsG & 240 & 30 & 15.54 & 8.000 & 21.54 & 55.13 \\
\hline & $\operatorname{trp}$ & 144 & 25 & 12.95 & 5.760 & 14.73 & 39.20 \\
\hline & $\operatorname{car} \mathrm{A}$ & 60 & 20 & 10.36 & 3.000 & 3.810 & 3.000 \\
\hline & hsdR & 23 & 19 & 9.840 & 1.210 & 0.5600 & 0 \\
\hline \multirow[t]{4}{*}{ DNAs } & DNA & 1839 & 137 & 70.98 & 13.42 & 16.31 & 19.69 \\
\hline & plasmid DNA & 193 & 36 & 18.65 & 5.360 & 12.31 & 28.80 \\
\hline & chromosomal DNA & 63 & 24 & 12.44 & 2.630 & 2.440 & 2.000 \\
\hline & CDNA & 125 & 23 & 11.92 & 5.430 & 5.820 & 5.000 \\
\hline \multirow[t]{10}{*}{ RNAs } & RNA & 4193 & 140 & 72.54 & 29.95 & 38.21 & 49.79 \\
\hline & uncharged tRNA & 1168 & 117 & 60.62 & 9.980 & 19.64 & 40.11 \\
\hline & rRNA & 1116 & 97 & 50.26 & 11.51 & 25.97 & 56.82 \\
\hline & a mRNA & 999 & 91 & 47.15 & 10.98 & 19.52 & 36.10 \\
\hline & $r \mathrm{rnA}$ & 911 & 87 & 45.08 & 10.47 & 22.51 & 48.40 \\
\hline & stable RNA & 430 & 87 & 45.08 & 4.940 & 8.030 & 16.00 \\
\hline & a charged tRNA & 140 & 43 & 22.28 & 3.260 & 4.200 & 5.330 \\
\hline & $\mathrm{rrnB}$ & 301 & 26 & 13.47 & 11.58 & 19.30 & 32.82 \\
\hline & $\mathrm{rrn}$ & 321 & 26 & 13.47 & 12.35 & 30.42 & 75.00 \\
\hline & 16s-rRNAs & 156 & 25 & 12.95 & 6.240 & 9.090 & 13.50 \\
\hline
\end{tabular}

Individual genetic components (i.e. genes, DNAs and RNAs) were evaluated considering the number of documents where these entities were annotated and their number of annotations in the corpus. Statistical measurements are detailed in the Methods and Materials section.

$\psi$ A threshold of $10 \%$ of the frequency of annotation was set for each genetic component category. However, lists of all annotated entities are provided in Additional file 5 .

VMR: variance-to-mean

Std: standard deviation

RNA (PMID: 2209559; PMID: 9973355) ${ }^{1}$ [33-35], was highly annotated (with a mean of almost 50 annotations per document), but presented a low frequency (less than $10 \%$ of the documents). The extreme value of VMR (over 150) pointed out that some of these documents are devoted to the discussion of this biological entity, which contributed to the large annotation of this concept.
The analysis of the annotation of small molecules (see Table 3) revealed that, though almost $83 \%$ of the documents discussed the general role of amino acids and nucleotides, the mean of annotation of specific nucleotides and amino acids was quite low (less than 10 annotations per document in most cases). The two exceptions were the nucleotides ppGpp and (p)ppGpp (the collective reference for ppGpp and pppGpp). A 
Table 2 Annotations of the gene products in the corpus.

\begin{tabular}{|c|c|c|c|c|c|c|c|}
\hline Class & Concept & $\begin{array}{l}\text { Number of } \\
\text { Annotations }\end{array}$ & $\begin{array}{l}\text { Number of } \\
\text { Documents }\end{array}$ & $\begin{array}{l}\text { \% Frequency (Eq. } \\
1)^{\psi}\end{array}$ & $\begin{array}{l}\text { Mean (Eq. } \\
\text { 2) }\end{array}$ & $\begin{array}{l}\text { Std (Eq. } \\
\text { 3) }\end{array}$ & $\begin{array}{l}\text { VMR (Eq. } \\
4)\end{array}$ \\
\hline \multirow[t]{11}{*}{ Proteins } & Ribosome & 1643 & 128 & 66.32 & 12.84 & 23.57 & 44.08 \\
\hline & $\overline{\text { Rel }}$ & 1021 & 62 & 32.12 & 16.50 & 36.60 & 81.00 \\
\hline & LacZ & 543 & 53 & 27.46 & 10.30 & 17.44 & 28.90 \\
\hline & Sigma 38 factor & 392 & 42 & 21.76 & 9.330 & 15.40 & 25.00 \\
\hline & Sigma factor & 112 & 35 & 18.13 & 3.200 & 5.870 & 8.330 \\
\hline & $\overline{U v r D}$ & 56 & 35 & 18.13 & 1.600 & 1.300 & 1.000 \\
\hline & RpoB & 252 & 35 & 18.13 & 7.200 & 11.50 & 17.29 \\
\hline & $\operatorname{Rec} A$ & 99 & 31 & 16.06 & 3.190 & 4.260 & 5.330 \\
\hline & EF-Tu & 223 & 26 & 13.47 & 8.580 & 17.32 & 36.13 \\
\hline & $\overline{\text { Der }}$ & 51 & 25 & 12.95 & 2.040 & 2.140 & 2.000 \\
\hline & Sigma 70 factor & 134 & 21 & 10.88 & 6.380 & 11.19 & 20.17 \\
\hline \multirow{7}{*}{$\begin{array}{l}\text { Transcription } \\
\text { factors }\end{array}$} & Fis & 888 & 18 & 9.330 & 49.33 & 86.88 & 150.9 \\
\hline & Fur & 56 & 13 & 6.740 & 4.310 & 9.260 & 20.25 \\
\hline & $\overline{C R P}$ & 279 & 12 & 6.220 & 23.25 & 36.28 & 56.35 \\
\hline & DnaA & 121 & 11 & 5.700 & 11.00 & 23.00 & 48.09 \\
\hline & $\mathrm{H}-\mathrm{NS}$ & 73 & 11 & 5.700 & 6.640 & 10.73 & 16.67 \\
\hline & LexA & 101 & 10 & 5.180 & 10.10 & 18.32 & 32.40 \\
\hline & $\mathrm{IHF}$ & 54 & 9 & 4.660 & 6.000 & 5.250 & 4.170 \\
\hline \multirow[t]{12}{*}{ Enzymes } & RelA & 4138 & 152 & 78.76 & 27.22 & 31.16 & 35.59 \\
\hline & $\overline{R N A P}$ & 1873 & 117 & 60.62 & 16.01 & 28.08 & 49.00 \\
\hline & SpoT & 1024 & 60 & 31.09 & 17.07 & 42.19 & 103.8 \\
\hline & $\overline{\text { EcoRl }}$ & 215 & 53 & 27.46 & 4.060 & 4.970 & 4.000 \\
\hline & $\beta$-galactosidase & 294 & 47 & 24.35 & 6.260 & 6.550 & 6.000 \\
\hline & BamHI & 149 & 43 & 22.28 & 3.470 & 5.870 & 8.330 \\
\hline & HindIII & 114 & 41 & 21.24 & 2.780 & 2.160 & 2.000 \\
\hline & RNase & 109 & 36 & 18.65 & 3.030 & 4.280 & 5.330 \\
\hline & YbcS & 50 & 23 & 11.92 & 2.170 & 2.620 & 2.000 \\
\hline & $\begin{array}{l}\text { Reverse } \\
\text { transcriptase }\end{array}$ & 34 & 21 & 10.88 & 1.620 & 1.050 & 1.000 \\
\hline & tRNA synthetase & 54 & 20 & 10.36 & 2.700 & 2.630 & 2.000 \\
\hline & Endonuclease I & 29 & 20 & 10.36 & 1.450 & 1.400 & 1.000 \\
\hline
\end{tabular}

Individual gene products (i.e. enzymes, transcription factors and other proteins) were evaluated considering the number of documents where these entities were annotated and their number of annotations in the corpus. Statistical measurements are detailed in the Methods and Materials section.

${ }^{*}$ A threshold of $10 \%$ of the frequency of annotation was set for enzymes and other proteins, whereas a threshold of $5 \%$ was set for transcription factors.

However, lists of all annotated entities are provided in Additional file 6.

VMR: variance-to-mean

Std: standard deviation

high frequency ( $75 \%$ and $37 \%$, respectively) and mean of annotation (29 and 43, respectively) confirm that these nucleotides are central in the stringent response in $E$. coli. Indeed, during amino acid starvation (p)ppGpp nucleotides coordinate several cellular activities by influencing gene expression.

Taking these results into account, the frequency of coannotation of these nucleotides with gene products was evaluated. As mentioned above, it can be admitted that the co-occurrence of two concepts $\left(t_{i}\right.$ and $\left.t_{j}\right)$ in the same body text might indicate a relationship between them (even if indirect). Thus, to find key players in the stringent response that are possibly affected by the accumulation of (p)ppGpp nucleotides, the frequency of coannotation of concepts for gene products and each of these nucleotides was estimated. As shown in Figure 3 and Additional file 3, (p)ppGpp nucleotides were found to be considerably co-annotated with highly representative proteins, namely: the RelA and SpoT enzymes that control the basal levels of the nucleotides (in 93\% and 
Table 3 Annotations of the small molecules in the corpus.

\begin{tabular}{|c|c|c|c|c|c|c|}
\hline Concept & $\begin{array}{l}\text { Number of } \\
\text { Annotations }\end{array}$ & $\begin{array}{l}\text { Number of } \\
\text { Documents }\end{array}$ & $\begin{array}{l}\text { \% Frequency of annotation } \\
(\text { Eq. } 1)^{\psi}\end{array}$ & $\begin{array}{l}\text { Mean of annotation } \\
\text { (Eq. 2) }\end{array}$ & $\begin{array}{l}\text { Std (Eq. } \\
3)\end{array}$ & $\begin{array}{l}\text { VMR (Eq. } \\
\text { 4) }\end{array}$ \\
\hline Amino acids & 1557 & 160 & 82.90 & 9.730 & 13.83 & 18.78 \\
\hline Nucleotides & 1230 & 145 & 75.13 & 8.480 & 9.290 & 10.13 \\
\hline$\overline{p p G p p}$ & 4159 & 145 & 75.13 & 28.68 & 31.00 & 34.32 \\
\hline$\beta$-D-glucose & 792 & 123 & 63.73 & 6.440 & 10.63 & 16.67 \\
\hline$\overline{\mathrm{Pi}}$ & 662 & 113 & 58.55 & 5.860 & 12.60 & 28.80 \\
\hline Guanosine & 407 & 112 & 58.03 & 3.630 & 3.540 & 3.000 \\
\hline$\overline{\text { ATP }}$ & 587 & 100 & 51.81 & 5.870 & 7.410 & 9.800 \\
\hline GTP & 748 & 91 & 47.15 & 8.220 & 13.85 & 21.13 \\
\hline$\overline{\mathrm{AMP}}$ & 598 & 90 & 46.63 & 6.640 & 10.09 & 16.67 \\
\hline $\mathrm{PPi}$ & 447 & 87 & 45.08 & 5.140 & 5.180 & 5.000 \\
\hline $\mathrm{H}_{2} \mathrm{O}$ & 210 & 83 & 43.01 & 2.530 & 2.430 & 2.000 \\
\hline Tris & 261 & 82 & 42.49 & 3.180 & 2.800 & 1.330 \\
\hline Carbon & 288 & 80 & 41.45 & 3.600 & 4.850 & 5.330 \\
\hline Chloramphenicol & 435 & 77 & 39.90 & 5.650 & 8.250 & 12.80 \\
\hline pppGpp & 632 & 74 & 38.34 & 8.540 & 13.61 & 21.13 \\
\hline (p)ppGpp & 3127 & 72 & 37.31 & 43.43 & 56.00 & 72.93 \\
\hline $\mathrm{NaCl}$ & 189 & 67 & 34.72 & 2.820 & 2.790 & 2.000 \\
\hline L-lactate & 413 & 65 & 33.68 & 6.350 & 20.84 & 66.67 \\
\hline Glycerol & 145 & 65 & 33.68 & 2.230 & 1.850 & 0.5000 \\
\hline Ethanol & 189 & 65 & 33.68 & 2.910 & 4.400 & 8.000 \\
\hline$\overline{\mathrm{Na}^{+}}$ & 145 & 63 & 32.64 & 2.300 & 2.100 & 2.000 \\
\hline Ampicillin & 321 & 62 & 32.12 & 5.180 & 12.74 & 28.80 \\
\hline EDTA & 142 & 60 & 31.09 & 2.370 & 1.680 & 0.5000 \\
\hline L-methionine & 248 & 59 & 30.57 & 4.200 & 6.670 & 9.000 \\
\hline L-histidine & 183 & 59 & 30.57 & 3.100 & 5.410 & 8.330 \\
\hline L-valine & 396 & 57 & 29.53 & 6.950 & 11.90 & 20.17 \\
\hline Formate & 136 & 57 & 29.53 & 2.390 & 2.360 & 2.000 \\
\hline
\end{tabular}

Individual small molecules were evaluated considering the number of documents where these entities were annotated and the number of annotations in the corpus. Statistical measurements are detailed in the Methods and Materials section.

${ }^{\psi}$ A threshold of $30 \%$ of the frequency of annotation was set for compounds. However, lists of all annotated entities are provided in Additional file 7. VMR: variance-to-mean

Std: standard deviation

$67 \%$ of the (p)ppGpp-annotated documents, respectively); ribosomes that are affected by the nucleotides activity (in approximately $79 \%$ of the (p)ppGpp-annotated documents); RNAP (in approximately $64 \%$ of the (p)ppGpp-annotated documents); and the RpoS, the alternative sigma factor $\sigma^{38}$ that acts as the master regulator of the general stress response (in approximately $40 \%$ of the (p)ppGpp-mentioning documents) (PMID: 9326588) [35]. Some proteins were co-annotated with only one or two of the concepts. For instance, the Gpp enzyme that converts pppGpp into ppGpp (PMID: 8531889; PMID: 6130093) [36,37] was essentially coannotated with the pppGpp concept. In turn, the RecA protein, which catalyses DNA strand exchange reactions (PMID: 17590232) [38], and the tRNA synthetase were co-annotated with (p)ppGpp and ppGpp with a frequency higher than $10 \%$, whereas other proteins were mainly co-annotated with (p)ppGpp and pppGpp: the elongation factor (EF) G, known to facilitate the translocation of the ribosome along the mRNA molecules (PMID: 8531889) [36]; the RplK (or 50S ribosomal subunit protein L11) that was reported to be essential when the $30 \mathrm{~S}$ ribosomal initiation complex joins to the $50 \mathrm{~S}$ ribosomal subunit and in the EF-G-dependent GTPase activity (PMID: 17095013; PMID: 12419222) [39,40]; and the enzyme PhoA known to be involved in the acquisition and transport of phosphate (PMID: 9555903) [41].

Additionally, results pointed out potentially interesting associations with less represented proteins (see Additional file 3), such as: the Fur transcriptional activator that controls the transcription of genes involved in iron 


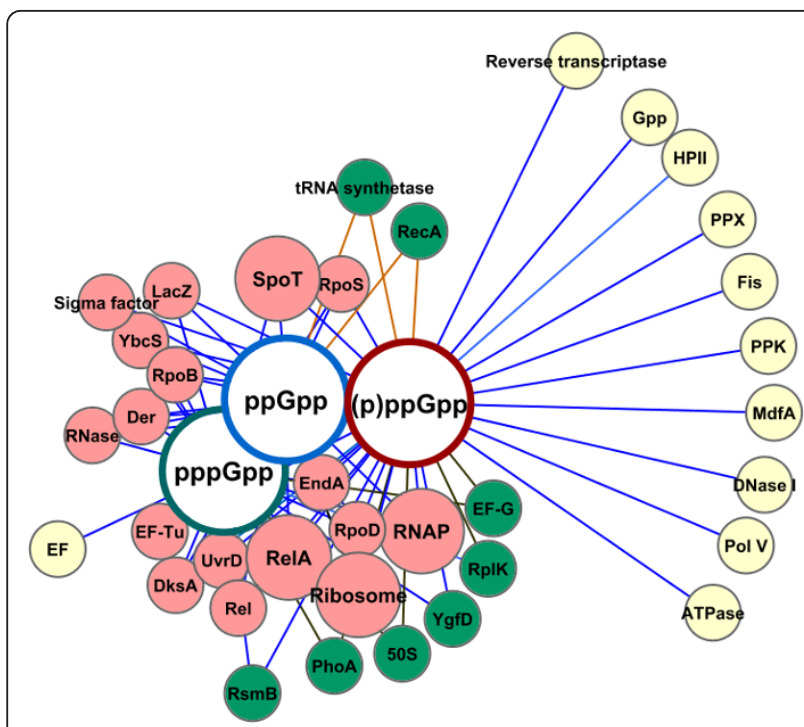

Figure 3 Proteins co-annotated with ppGpp, pppGpp and the collective (p)ppGpp entities. The nodes represent proteins with frequency of co-annotation higher than 10\%. Highly co-annotated proteins are represented by nodes with a larger size (frequencies of co-annotation greater than 50\%). Pink nodes represent the proteins that were co-annotated with the three entities, while green and yellow nodes indicate the proteins that were co-annotated with only two and one of the nucleotides, respectively.

homeostasis (PMID: 15853883) [42]; the HN-S transcriptional dual regulator that is capable of condensing and supercoiling DNA (PMID: 10966109) [43]; the DnaA protein implicated in the chromosomal replication initiation (PMID:1690706) [44]; the DinJ-YafQ complex involved in the inhibition of protein synthesis and growth (PMID:12123445) [12] and the MazE antitoxin of the MazF-MazE toxin-antitoxin system involved in translation inhibition processes (PMID:12123445) [12]. In general, most co-annotated entities correspond to gene products that have regulatory functions in the gene transcription process, such as transcriptional factors, or that are components of the translational apparatus.

\section{Examining less-reported entities}

In the present corpus, most of the biological entities identified as major participants in the $E$. coli stringent response, were also extensively cited in recent reviews $[9,11,17,24,25]$ (see Additional file 4). These reviews were selected based on their relevance in terms of information specifically collected for the stringent response in E. coli and their number of citations. As illustrated in Figure 4, biological concepts considered to be key components in those reviews were also evidenced by the semi-automatic information extraction approach.

However, when examining the extent of annotated concepts from the selected reviews and the corpus, it was evident that many biological entities have been disregarded or less reported in the reviews. Biological entities, such as transcriptional factors and other gene products like stress-related proteins, were not described in the selected reviews. Indeed, often the role of some biological entities that are directly (or indirectly) associated with the stringent response, is missing in most literature revisions. To illustrate this, we compiled information on the participation of some less-reported biological entities in $E$. coli stringent response by validating their role. These results can be found in Table 4 .

The recognition of these proteins in the corpus was invaluable, allowing to uncover various stress-responsive proteins, such as chaperones (e.g. DnaJ, ClpB or the GroEL-GroES chaperonin complex) and toxin-antitoxin systems (e.g. protein encoded by $\operatorname{ch} p \mathrm{R}$ ) that are normally associated with other stress responses. The description of such entities as participants in the stringent response discloses a more insightful overview of the complexity of these entangled cellular processes. For example, the identification of entities related to certain metabolic pathways, like the fatty acids biosynthesis (e.g. FabH and FabR), or DNA processes, like DNA replication (e.g. CspD) and DNA repair (e.g. $u v r \mathrm{Y})$, can expand the characterization of stringently regulated activities that have not been evident in previous reviews.

\section{Evolution of technology versus knowledge}

From the previous results it is clear that studies on the stringent response were essentially focused on the characterizations of the catalytic activities of the enzymes RelA and SpoT and their role in the control of (p) ppGpp accumulation. Though these processes are central in the stringent response, the global effects of the (p)ppGpp-dependent response are of primordial importance. The influence on transcription and translation processes and the triggering of other stress responses have raised interest from researchers.

As such, the investigation of many other biological entities and their roles during the stringent response has driven research to the systems-wide understanding of this complex regulatory networks [12]. Only with the development of more sophisticated techniques, like peptide mass fingerprinting (MI:0082) or chromatin immunoprecipitation arrays (MI:0225), it was possible to investigate the complexity of biological systems in a high throughput manner. The development of experimental techniques was a key point in this transition and it is expected to intersect points of turnover on the study of the stringent response. We could confirm that with the availability of more experimental techniques, the extent of biological concepts annotated in our corpus increased. By comparing the number of annotations of biological concepts (genetic components, gene 


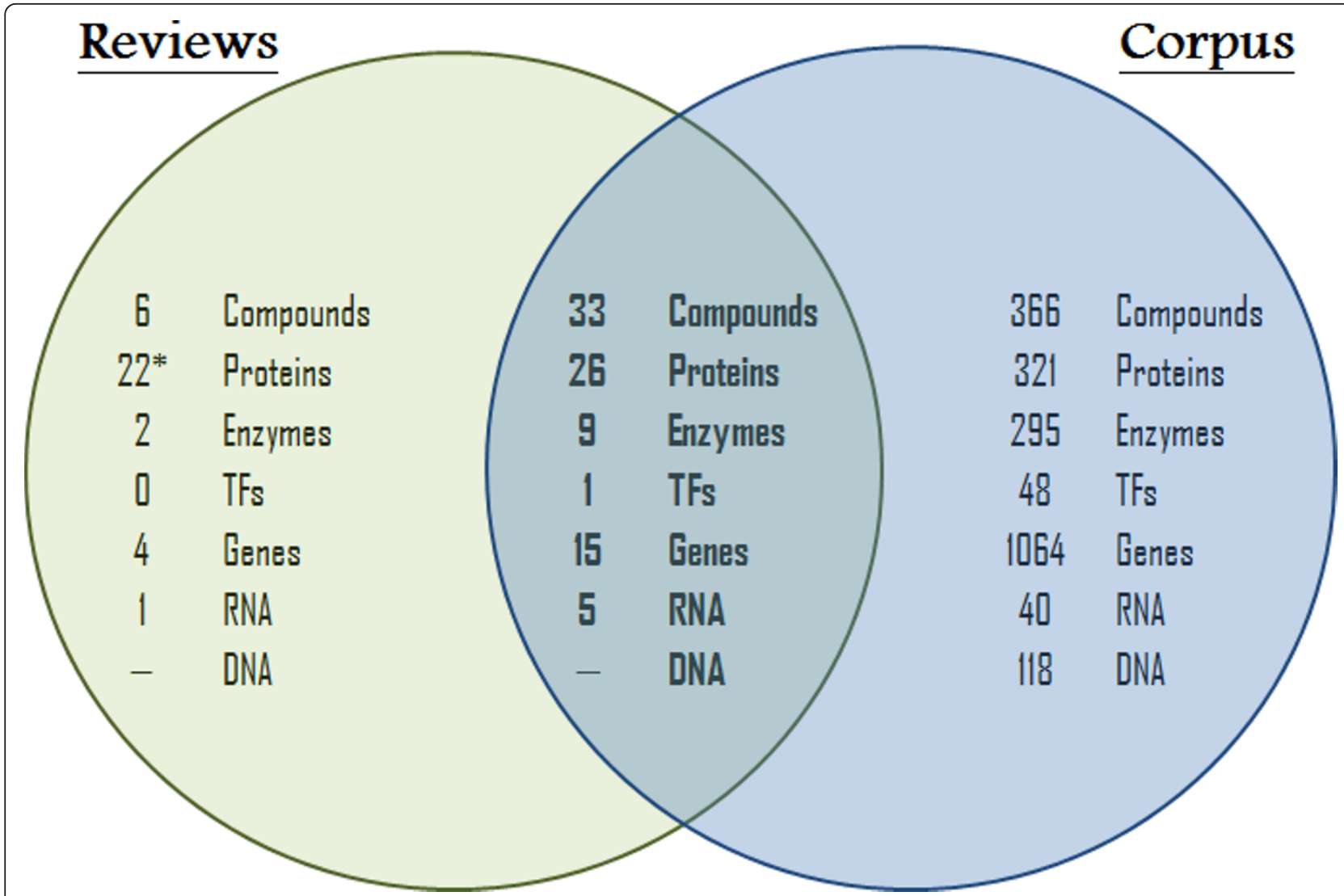

Figure 4 Venn diagram comparing annotations from corpus and selected reviews. This diagram indicates the number of biological concepts per class that represent the corpus and from the latest reviews considered to be relevant to this subject. The intersecting zone gives the number of biological concepts that were simultaneously reported in the two set of documents.

products and small molecules) and experimental techniques (grouped into major PSI-MI classes) per decade (Figure 5) it is possible to verify the progression of knowledge related with the stringent response in $E$. coli.

The analysis evidenced that the repertoire of experimental techniques has been growing significantly and the study is ever more dedicated to the investigation of genetic components. In particular, results showed the use of an ever-growing number of experimental interaction detection methods (MI:0045) and a considerable number of experimental participant identification (MI:0661) and experimental feature detection (MI:0659) methods. The analysis of annotated experimental techniques in the corpus (Table 5) evidenced that the chromatography technology (MI:0091), experimental feature detection (MI:0657), genetic interference (MI:0254) and primer specific polymerase chain reaction (PCR) (MI:0088) techniques were annotated in more than $40 \%$ of the documents. Most techniques were referred roughly two times per document, but primer-specific PCR (MI:0088) and array technology (MI:0008) presented a considerable mean of annotation (with over 10 and 8 annotations per document, respectively) and high VMR values (22.5 and 6.13, respectively), which indicated that these techniques were essentially discussed in a given set of documents.

A detailed look into the frequency of concept annotation per decade points out that some of the techniques used in early studies have a reduced application today and highlights the increasing influence of high-throughput technologies in recent studies. For instance, experimental interaction detection methods (MI:0045), such as the scintillation proximity assay (MI:0099), the molecular sieving (MI:0071), the filter trap assays (MI:0928) and the cosedimentation through density gradient (MI:0029) were mostly annotated in documents from the first decade (1970-1980), whereas the comigration in gel electrophoresis (MI:0807) and enzymatic studies (MI:0415) were increasingly reported in documents throughout the decades.

\section{Functional enrichment}

Recent developments in the functional annotation of genomes using biological ontologies provided the means 
Table 4 Some examples of less-reported entities (namely in recent reviews), which are relevant in the $E$. coli stringent response.

\begin{tabular}{|c|c|c|c|}
\hline Biological entities & $\begin{array}{c}\text { Freq } \\
(\%)\end{array}$ & Details & References \\
\hline DnaJ - chaperone with DnaK & 3.11 & $\begin{array}{l}\text { Chaperone protein that assists the DnaJ/DnaK/GrpE system of E. coli. The overproduction } \\
\text { of ppGpp has shown to induce the accumulation of these chaperones. }\end{array}$ & [68] \\
\hline ClpB chaperone & 1.55 & $\begin{array}{l}\text { ClpB, together with the DnaJ/DnaK/GrpE chaperone system, is able to resolubilize } \\
\text { aggregated proteins. }\end{array}$ & [69] \\
\hline GroEL-GroES chaperonin complex & 0.52 & GroEL and GroES are both induced by heat and when ppGpp is overproduced in E. coli. & [68] \\
\hline $\begin{array}{l}\text { RuvB - branch migration of Holliday } \\
\text { structures; repair helicase }\end{array}$ & 1.55 & $\begin{array}{l}\text { Component of the RuvABC enzymatic complex that promotes the rescue of stalled } \\
\text { (often formed by ppGpp) or broken DNA replication forks in E. coli. }\end{array}$ & [70] \\
\hline CsrA - carbon storage regulator & 1.04 & $\begin{array}{l}\text { Regulator of carbohydrate metabolism, which activates UvrY, responsible for the } \\
\text { transcription of csrB that, in turn, inhibits the CsrA activity. }\end{array}$ & [71] \\
\hline uvrY & 0.52 & $\begin{array}{c}\text { Encodes the UvrY protein that has been shown to be the cognate response regulator for } \\
\text { the BarA sensor protein. This regulator participates in controlling several genes involved } \\
\text { in the DNA repair system (e.g. CsrA) and carbon metabolism. }\end{array}$ & [72] \\
\hline cstA & 0.52 & $\begin{array}{l}\text { Gene encoding the CstA peptide transporter, which expression is induced by carbon } \\
\text { starvation and requires the CRP-cAMP transcriptional regulator. The CstA translation is } \\
\text { regulated by the CsrA that occludes ribosome binding to the CstA mRNA. }\end{array}$ & [73] \\
\hline CspD - DNA replication inhibitor & 0.52 & $\begin{array}{l}\text { CspD is a toxin that appears to inhibit the DNA replication. ppGpp is one of the positive } \\
\text { factors for the expression of cspD. }\end{array}$ & [74] \\
\hline FabH - $\beta$-ketoacyl-ACP synthase III & 0.52 & $\begin{array}{l}\text { A key enzyme in the initiation of fatty acids biosynthesis that is stringently regulated by } \\
\text { ppGpp. }\end{array}$ & {$[75]$} \\
\hline FadR transcriptional dual regulator & 1.55 & $\begin{array}{l}\text { Regulates the fatty acid biosynthesis and fatty acid degradation at the level of } \\
\text { transcription. ppGpp has been shown to be also involved in the regulation of these } \\
\text { pathways }\end{array}$ & [75] \\
\hline $\begin{array}{l}\text { NtrC-Phosphorylated transcriptional } \\
\text { dual regulator }\end{array}$ & 1.04 & $\begin{array}{l}\text { Regulatory protein involved in the assimilation of nitrogen and in slow growth caused } \\
\text { by N-limited condition. It was reported that ppGpp levels increase upon nitrogen } \\
\text { starvation. }\end{array}$ & [76] \\
\hline$d p s$ & 2.59 & $\begin{array}{l}\text { Gene encoding the Dps protein that is highly abundant in the stationary-phase and is } \\
\text { required for the starvation responses. It was found to be regulated by ppGpp and RpoS. }\end{array}$ & {$[77,78]$} \\
\hline psiF & 2.07 & $\begin{array}{l}\text { Gene induced during phosphate starvation that has been associated with the } \\
\text { accumulation of ppGpp. }\end{array}$ & [41] \\
\hline $\operatorname{chpR}$ & 2.07 & $\begin{array}{c}\text { Encodes the MazE antitoxin, a component of the MazE-MazF system that causes a } \\
\text { "programmed cell death" in response to stresses, including starvation. Genes mazE and } \\
\text { mazF are located in the E. coli rel operon and are regulated by ppGpp. }\end{array}$ & [79] \\
\hline mazG & 0.52 & $\begin{array}{c}\text { Encodes the MazG nucleoside pyrophosphohydrolase that limits the detrimental effects } \\
\text { of the MazF toxin under nutritional stress conditions. Overexpression of mazG inhibits } \\
\text { cell growth and negatively affects accumulation of ppGpp. }\end{array}$ & [80] \\
\hline
\end{tabular}

to contextualise literature mining outputs. The automatic mapping of annotated concepts to ontology terms was facilitated by EcoCyc database information that supports the assignment of MultiFun and GO ontology terms to genes and gene products. MultiFun ontology classifies gene products according to their cellular function, namely: metabolism, information transfer, regulation, transport, cell processes, cell structure, location, extra-chromosomal origin, DNA site, and cryptic gene. In turn, GO embraces three separate ontologies: cellular components, i.e. the parts of a cell or its extracellular environment; molecular functions, i.e. the basic activities of a gene product at the molecular level, such as binding or catalysis; and biological processes, i.e. the set of molecular events related to the integrated functioning of cells, tissues, organs or organisms.
Here, we have analysed the assignments for MultiFun cellular functions and GO biological processes (Table 6 and Table 7). The aim was to find statistically overrepresented ontology terms related with cellular functions and biological processes within the set of annotated concepts. Seemingly to what is proposed in some bioinformatics tools $[45,46]$, where gene expression datasets are analysed to find statistically over- or under-represented terms, we have estimated the frequency of ontology terms assigned to annotated concepts in the corpus (regarding both gene and gene products). For calculating this frequency of assignment, the fraction of documents in the corpus that included those ontology terms was also considered. For example, if a GO term is assigned to one or more concepts that altogether were annotated in $80 \%$ of the 


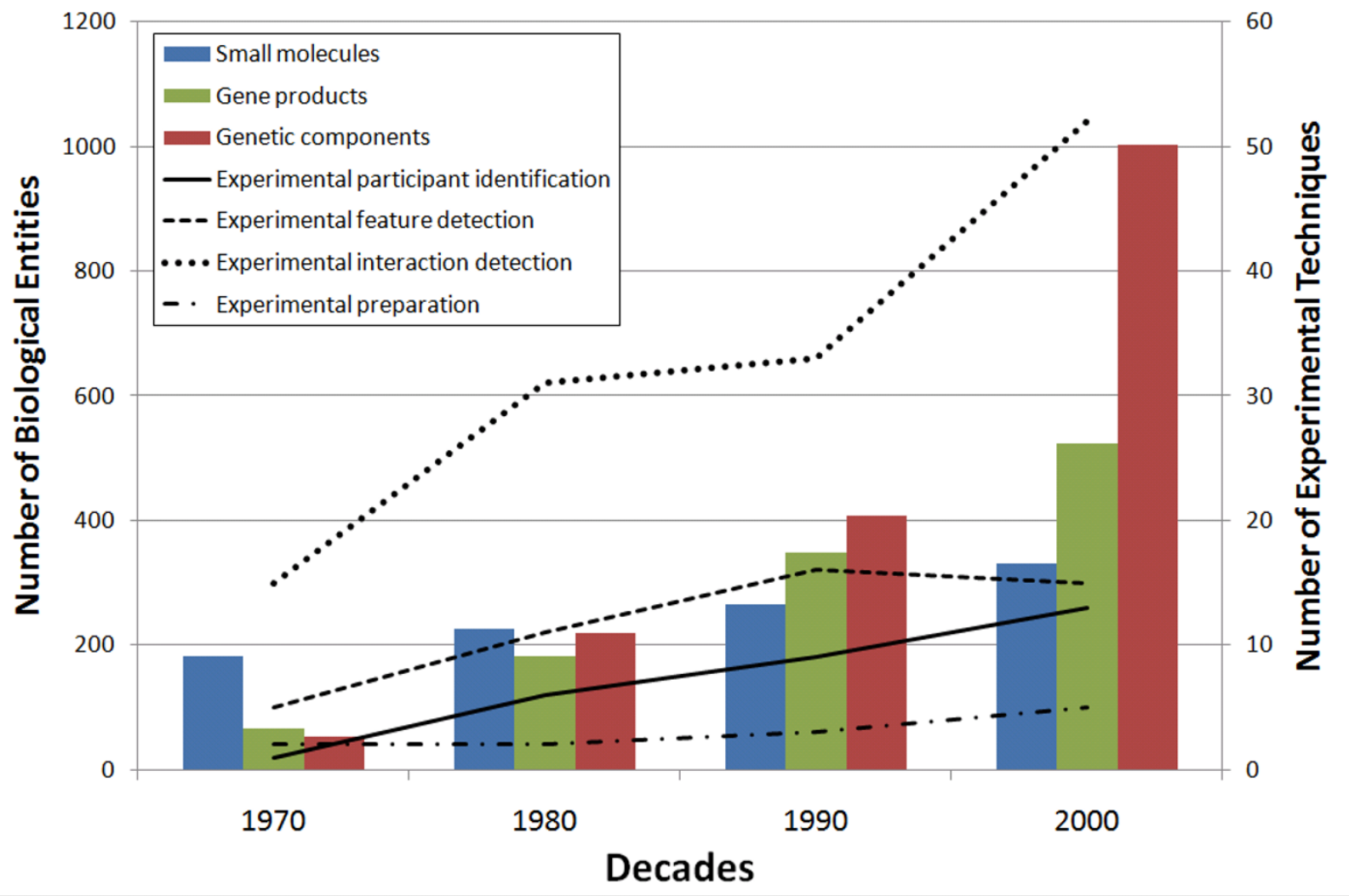

Figure 5 Comparison of the expansion of knowledge to the applied experimental techniques. Bars represent the number of biological entities (left $Y$ axis) found for the three major biological classes, i.e., genetic components (genes, RNAs and DNAs), gene products (proteins, transcription factors and enzymes) and small molecules. Lines plot the number of experimental techniques (right $Y$ axis) associated to the annotated PSI-MI classes.

documents, than the frequency of assignment of that ontology term in the corpus is $80 \%$.

We have also evaluated the contribution of concept annotations to the assignment of an ontology term. The frequency of annotation of a given term (A) by a given concept (B) was therefore estimated based on the ratio of the number of annotations of the concept (B) by the number of times that ontology term (A) was assigned by any concept associated to that term (A). Since one concept can be associated to several ontology terms, it can be considered that the under- or over-representation of an ontology term can depend on the number of annotations of the assigned concepts. In this perspective, concepts that were highly annotated in the corpus were considered the most relevant for the assignment of an ontology term. In summary, we estimate which are the most important cellular processes involved in the stringent response and also the key biological concepts involved in these processes.
The analysis of MultiFun cellular function assignments (Table 6) evidenced gene functions related to central metabolism processes, post-transcriptional processes and transcription-related functions (covered by over $50 \%$ of the documents). The most assigned MultiFun cellular functions, namely metabolic functions related to nucleotide and nucleoside conversions (BC-1.7.33) and proteolytic cleavage of compounds (BC-3.1.3.4), derived from the highly annotated relA and spoT genes. The lacZ gene, another highly annotated gene (26\% of the documents), that encodes the $\beta$-galactosidase enzyme responsible for the hydrolysis of $\beta$-galactosides into monosaccharides, contributed significantly (almost 50\% of assignments) to the annotation of cellular functions implicated in the metabolism of carbon compounds (BC-1.1.1). However, in this particular case it should be acquainted that the occurrence of this gene in documents is frequently associated with molecular assays using $l a c \mathrm{Z}$ as a reporter gene. Therefore, the relevance 
Table 5 PSI-MI assignments to annotated experimental techniques.

\begin{tabular}{|c|c|c|c|c|c|c|c|c|c|c|}
\hline \multirow{2}{*}{$\begin{array}{l}\text { Techniques } \\
\text { PSI-MI Class }\end{array}$} & \multirow[b]{2}{*}{$\begin{array}{l}\text { PSI-MI } \\
\text { id }\end{array}$} & \multirow[b]{2}{*}{ PSI-MI name } & \multicolumn{3}{|c|}{$\begin{array}{l}\text { Statistics over the } \\
\text { corpus }\end{array}$} & \multirow[b]{2}{*}{ VMR } & \multicolumn{4}{|c|}{ Frequency per Decade } \\
\hline & & & Freq & Mean & Std & & 1970 & 1980 & 1990 & 2000 \\
\hline \multirow[t]{6}{*}{ MI:0659 experimental feature detection } & Ml:0659 & experimental feature detection* & $55 \%$ & 2.44 & 2.76 & 2 & $64 \%$ & $65 \%$ & $67 \%$ & $67 \%$ \\
\hline & Ml:0833 & autoradiography & $25 \%$ & 1.65 & 1.4 & 1 & $29 \%$ & $35 \%$ & $22 \%$ & $22 \%$ \\
\hline & Ml:0113 & western blot & $21 \%$ & 4.95 & 3.38 & 2.25 & - & $13 \%$ & $18 \%$ & $44 \%$ \\
\hline & MI:0074 & mutation analysis & $20 \%$ & 3.34 & 3.24 & 3 & $14 \%$ & $20 \%$ & $27 \%$ & $32 \%$ \\
\hline & Ml:0114 & x-ray crystallography & $4 \%$ & 1.63 & 1.46 & 1 & - & - & $2 \%$ & $8 \%$ \\
\hline & Ml:0811 & insertion analysis & $4 \%$ & 1.14 & 0.38 & 0 & - & - & $7 \%$ & $4 \%$ \\
\hline \multirow{35}{*}{$\begin{array}{l}\text { Ml:0045 experimental interaction } \\
\text { detection }\end{array}$} & MI:0091 & chromatography technology & $50 \%$ & 4.23 & 4.14 & 4 & $100 \%$ & $85 \%$ & $55 \%$ & $64 \%$ \\
\hline & Ml:0254 & genetic interference & $42 \%$ & 2.68 & 2.35 & 2 & - & $28 \%$ & $69 \%$ & $64 \%$ \\
\hline & MI:0807 & comigration in gel electrophoresis & $37 \%$ & 2.51 & 2.13 & 2 & $21 \%$ & $48 \%$ & $51 \%$ & $49 \%$ \\
\hline & Ml:0045 & experimental interaction detection* & $36 \%$ & 3.1 & 3.12 & 3 & $14 \%$ & $45 \%$ & $47 \%$ & $41 \%$ \\
\hline & Ml:0808 & comigration in sds page & $27 \%$ & 2.02 & 1.61 & 0.5 & $7 \%$ & $23 \%$ & $33 \%$ & $29 \%$ \\
\hline & Ml:0099 & scintillation proximity assay & $24 \%$ & 1.94 & 1.65 & 1 & $64 \%$ & $35 \%$ & $20 \%$ & $15 \%$ \\
\hline & Ml:0051 & fluorescence technology & $16 \%$ & 1.84 & 1.8 & 1 & $7 \%$ & $20 \%$ & $5 \%$ & $22 \%$ \\
\hline & Ml:0071 & molecular sieving & $15 \%$ & 2.25 & 3.19 & 4.5 & $29 \%$ & $13 \%$ & $15 \%$ & $13 \%$ \\
\hline & Ml:0217 & phosphorylation reaction & $13 \%$ & 2.72 & 3.74 & 4.5 & $7 \%$ & $8 \%$ & $16 \%$ & $14 \%$ \\
\hline & Ml:0415 & enzymatic study & $12 \%$ & 1.96 & 2.11 & 4 & $7 \%$ & $8 \%$ & $11 \%$ & $19 \%$ \\
\hline & Ml:0008 & array technology & $10 \%$ & 8.47 & 7.47 & 6.13 & - & - & - & $22 \%$ \\
\hline & MI:0928 & filter trap assay & $9 \%$ & 2.24 & 2.47 & 2 & $36 \%$ & $13 \%$ & $4 \%$ & $6 \%$ \\
\hline & Ml:0004 & affinity chromatography technology & $8 \%$ & 2.33 & 2.44 & 2 & - & $5 \%$ & $5 \%$ & $13 \%$ \\
\hline & MI:0428 & imaging technique & $7 \%$ & 1.57 & 1.41 & 1 & - & $8 \%$ & $4 \%$ & $11 \%$ \\
\hline & MI:0047 & far western blotting & $6 \%$ & 1.5 & 0.82 & 0 & - & $3 \%$ & $7 \%$ & $8 \%$ \\
\hline & Ml:0435 & protease assay & $6 \%$ & 3.92 & 4.01 & 5.33 & - & $5 \%$ & $5 \%$ & $8 \%$ \\
\hline & Ml:0017 & classical fluorescence spectroscopy & $6 \%$ & 1.08 & 0.29 & 0 & - & - & $5 \%$ & $11 \%$ \\
\hline & Ml:0089 & protein array & $6 \%$ & 1.64 & 1.62 & 1 & - & $3 \%$ & $2 \%$ & $11 \%$ \\
\hline & Ml:0029 & $\begin{array}{l}\text { cosedimentation through density } \\
\text { gradient }\end{array}$ & $5 \%$ & 5.22 & 3.94 & 1.8 & $43 \%$ & $10 \%$ & - & $2 \%$ \\
\hline & MI:0040 & electron microscopy & $4 \%$ & 2.57 & 1.31 & 0.5 & - & $10 \%$ & - & $4 \%$ \\
\hline & Ml:0676 & tandem affinity purification & $3 \%$ & 3.8 & 5.18 & 8.33 & - & - & - & $7 \%$ \\
\hline & MI:0054 & fluorescence-activated cell sorting & $3 \%$ & 5.8 & 4.6 & 3.2 & - & - & $4 \%$ & $4 \%$ \\
\hline & Ml:0413 & electrophoretic mobility shift assay & $3 \%$ & 1.6 & 0.77 & 0 & - & - & $5 \%$ & $2 \%$ \\
\hline & Ml:0012 & $\begin{array}{l}\text { bioluminescence resonance energy } \\
\text { transfer }\end{array}$ & $2 \%$ & 6.25 & 5.68 & 4.17 & - & - & $4 \%$ & $2 \%$ \\
\hline & Ml:0018 & two hybrid & $2 \%$ & 2 & 1.41 & 0.5 & - & - & - & $7 \%$ \\
\hline & Ml:0053 & $\begin{array}{l}\text { fluorescence polarization } \\
\text { spectroscopy }\end{array}$ & $2 \%$ & 5 & 2.94 & 0.8 & - & $3 \%$ & - & $2 \%$ \\
\hline & Ml:0397 & two hybrid array & $2 \%$ & 2 & 1.41 & 0.5 & - & - & $2 \%$ & $2 \%$ \\
\hline & MI:0227 & reverse phase chromatography & $2 \%$ & 3.25 & 2.87 & 1.33 & - & - & $5 \%$ & $1 \%$ \\
\hline & Ml:0226 & ion exchange chromatography & $1 \%$ & 1 & 0 & 0 & - & - & - & $1 \%$ \\
\hline & Ml:0031 & $\begin{array}{l}\text { protein cross-linking with a } \\
\text { bifunctional reagent }\end{array}$ & $1 \%$ & 7 & 4 & 2.29 & - & $3 \%$ & - & $1 \%$ \\
\hline & Ml:0052 & fluorescence correlation spectroscopy & $1 \%$ & 1 & 0 & 0 & - & - & - & $1 \%$ \\
\hline & MI:0416 & fluorescence microscopy & $1 \%$ & 2.5 & 0.71 & 0 & - & - & - & $2 \%$ \\
\hline & Ml:0016 & circular dichroism & $1 \%$ & 1.5 & 0.71 & 0 & - & - & - & $2 \%$ \\
\hline & MI:0225 & chromatin immunoprecipitation array & $1 \%$ & 1 & 0 & 0 & - & - & - & $1 \%$ \\
\hline & Ml:0872 & atomic force microscopy & $1 \%$ & 1 & 0 & 0 & - & - & - & $1 \%$ \\
\hline
\end{tabular}


Table 5 PSI-MI assignments to annotated experimental techniques. (Continued)

\begin{tabular}{|c|c|c|c|c|c|c|c|c|c|c|}
\hline & Ml:0049 & filter binding & $1 \%$ & 1 & 0 & 0 & - & $3 \%$ & $2 \%$ & - \\
\hline & Ml:0426 & light microscopy & $1 \%$ & 1 & 0 & 0 & - & - & - & $2 \%$ \\
\hline \multirow{10}{*}{$\begin{array}{l}\text { MI:0661 experimental participant } \\
\text { identification }\end{array}$} & MI:0088 & primer specific pcr & $40 \%$ & 10.38 & 15.87 & 22.5 & - & $8 \%$ & $29 \%$ & $95 \%$ \\
\hline & Ml:0080 & $\begin{array}{l}\text { partial dna sequence identification by } \\
\text { hybridization }\end{array}$ & $27 \%$ & 3.75 & 3.47 & 3 & $14 \%$ & $30 \%$ & $29 \%$ & $26 \%$ \\
\hline & Ml:0078 & nucleotide sequence identification & $20 \%$ & 1.77 & 1.26 & 1 & - & $15 \%$ & $25 \%$ & $22 \%$ \\
\hline & Ml:0103 & southern blot & $14 \%$ & 3.04 & 2.05 & 1.33 & - & $8 \%$ & $15 \%$ & $19 \%$ \\
\hline & Ml:0929 & nothern blot & $8 \%$ & 5.56 & 4.8 & 3.2 & - & $3 \%$ & $11 \%$ & $11 \%$ \\
\hline & MI:0421 & identification by antibody & $6 \%$ & 1.82 & 1.51 & 1 & - & $8 \%$ & $5 \%$ & $6 \%$ \\
\hline & Ml:0427 & identification by mass spectrometry & $5 \%$ & 1.67 & 0.94 & 0 & - & - & $4 \%$ & $8 \%$ \\
\hline & Ml:0082 & peptide massfingerprinting & $2 \%$ & 1.5 & 0.71 & 0 & - & - & - & $5 \%$ \\
\hline & Ml:0093 & protein sequence identification & $1 \%$ & 1 & 0 & 0 & - & - & $2 \%$ & \\
\hline & Ml:0411 & enzyme linked immunosorbent assay & $1 \%$ & 4 & 2 & 1 & - & - & $2 \%$ & $1 \%$ \\
\hline \multirow[t]{4}{*}{ MI:0346 experimental preparation } & Ml:0714 & nucleic acid transduction & $26 \%$ & 2.22 & 2.82 & 2 & $14 \%$ & $15 \%$ & $31 \%$ & $29 \%$ \\
\hline & Ml:0715 & nucleic acid conjugation & $6 \%$ & 1.73 & 1.41 & 1 & $7 \%$ & $3 \%$ & $5 \%$ & $7 \%$ \\
\hline & Ml:0308 & electroporation & $5 \%$ & 1.89 & 1.56 & 1 & - & - & $2 \%$ & $9 \%$ \\
\hline & Ml:0343 & cdna library & $3 \%$ & 1 & 0 & 0 & - & - & - & $6 \%$ \\
\hline MI:0190 interaction type & MI:0194 & cleavage reaction & $1 \%$ & 1 & 0 & 0 & - & $3 \%$ & - & - \\
\hline Ml:0116 feature type & Ml:0373 & dye label & $5 \%$ & 1.2 & 0.45 & 0 & $7 \%$ & $8 \%$ & $5 \%$ & $4 \%$ \\
\hline
\end{tabular}

of this gene to the stringent response might be questionable.

The gene fis that encodes the Fis transcriptional dual regulator and the gene $r p o \mathrm{~B}$ coding for the $\beta$ subunit of the RNAP, contributed the most to the annotation of transcriptional related functions (BC-2.2.2). Similarly, genes like $d k s \mathrm{~A}$ that encodes the DksA protein, $r p l \mathrm{~K}$ that encodes the $50 \mathrm{~S}$ ribosomal subunit L11, and rpsG and rpsL coding for the $30 \mathrm{~S}$ ribosomal subunits S7 and $\mathrm{S} 12$, respectively, contributed the most to the annotation of translation related processes (BC-2.3.2). By looking into the frequencies, it was verified that there is a discrepancy of annotation between the genes contributing to enriched ontology terms and the corresponding gene products. Therefore, the use of the MultiFun ontology not only pointed out relevant gene function assignments, but also disclosed the participation of several gene products that, even being less reported in documents, were highlighted by functional association. Some examples are the 30S ribosomal subunit protein S12 and the $30 \mathrm{~S}$ ribosomal subunit protein $\mathrm{S} 7$ encoded by $r p s \mathrm{~L}$ and rpsG, respectively.

On the other hand, the analysis of GO biological process assignments (Table 7) highlighted metabolic and genetic information transfer processes as the most frequently assigned (i.e., over $50 \%$ of the documents have annotated concepts that were assigned to these ontology terms). Besides the general term "metabolic process" having the highest frequency (89\% of the documents), two particular terms associated with metabolic processes: the "nucleobase, nucleoside and nucleotide interconversion process" (GO:0015949) and the "guanosine tetraphosphate metabolic process" (GO:0015969), had high frequencies (around $80 \%$ of the documents) as well. The gene product that contributed the most to the annotation of terms related with metabolic processes was the RelA enzyme, with over $80 \%$ of the assignments. Regarding ontology terms related with genetic information transfer, "transcription" (GO:0006350), "DNAdependent transcription regulation" (GO:0006355) and "translation" (GO:0006412) were the most represented processes $(56 \%, 52 \%$ and $40 \%$ of the documents, respectively). The RpoS or the alternative sigma factor $\sigma^{38}$ that acts as the master regulator of the general stress response, the CRP transcriptional dual regulator, known to participate in the transcriptional regulation of genes involved in the degradation of non-glucose carbon sources and the Mfd protein, found to be responsible for ATP-dependent removal of stalled RNAPs from DNA, contributed similarly to the annotation of transcription and DNA-dependent transcription regulation processes, ranging between $10 \%$ and $20 \%$ of the assignments. Translation process assignments were derived from the RplK (or 50S ribosomal subunit protein L11) 
Table 6 MultiFun cellular function assignments.

\begin{tabular}{|c|c|c|c|c|c|c|c|}
\hline \multirow{2}{*}{$\begin{array}{l}\text { MultiFun } \\
\text { Concepts }\end{array}$} & \multirow{2}{*}{$\begin{array}{l}\text { Frequency of } \\
\text { Ontology } \\
\text { Annotation }\end{array}$} & \multirow[t]{2}{*}{ Brief Description } & \multicolumn{3}{|c|}{ Genes } & \multicolumn{2}{|c|}{ Gene Products } \\
\hline & & & Name & $\begin{array}{l}\text { Frequency } \\
\text { of } \\
\text { Assignment }\end{array}$ & $\begin{array}{c}\text { Frequency } \\
\text { of } \\
\text { Annotation }\end{array}$ & Name & $\begin{array}{c}\text { Frequency } \\
\text { of } \\
\text { Annotation }\end{array}$ \\
\hline \multirow[t]{2}{*}{$\begin{array}{l}\text { BC-1.7.33 } \\
\text { Nucleotide and } \\
\text { nucleoside } \\
\text { conversions }\end{array}$} & $76 \%$ & $\begin{array}{l}\text { The chemical reactions involved in the central carbon } \\
\text { metabolism by which a nucleobase, nucleoside or } \\
\text { nucleotide is converted from another nucleobase, } \\
\text { nucleoside or nucleotide. }\end{array}$ & relA & $68 \%$ & $72 \%$ & RelA & $79 \%$ \\
\hline & & & spoT & $28 \%$ & $46 \%$ & SpoT & $31 \%$ \\
\hline $\begin{array}{l}\text { BC-3.1.3.4 } \\
\text { Proteases, } \\
\text { cleavage of } \\
\text { compounds }\end{array}$ & $55 \%$ & $\begin{array}{l}\text { Proteins that hydrolysates a peptide bond or bonds } \\
\text { within a protein during posttranscriptional regulatory } \\
\text { processes. }\end{array}$ & spot & $91 \%$ & $46 \%$ & SpoT & $31 \%$ \\
\hline \multirow{2}{*}{$\begin{array}{l}\mathrm{BC}-2.2 .2 \\
\text { Transcription } \\
\text { related functions }\end{array}$} & $51 \%$ & $\begin{array}{l}\text { The information transfer related functions involved in } \\
\text { the synthesis of RNA on a template of DNA. }\end{array}$ & fis & $22 \%$ & $6 \%$ & Fis & $9 \%$ \\
\hline & & & rpoB & $17 \%$ & $16 \%$ & RpoB & $18 \%$ \\
\hline \multirow[t]{4}{*}{$\begin{array}{l}\text { BC-2.3.2 } \\
\text { Translation }\end{array}$} & $48 \%$ & $\begin{array}{l}\text { The cellular metabolic process by which a protein is } \\
\text { formed, using the sequence of a mature mRNA } \\
\text { molecule to specify the sequence of amino acids in a } \\
\text { polypeptide chain. }\end{array}$ & $d k s A$ & $23 \%$ & $3 \%$ & DksA & $8 \%$ \\
\hline & & & $r p / K$ & $17 \%$ & $6 \%$ & RplK & $7 \%$ \\
\hline & & & rpsG & $12 \%$ & $18 \%$ & RpsG & NA \\
\hline & & & rpsL & $11 \%$ & $19 \%$ & RpsL & $3 \%$ \\
\hline \multirow[t]{2}{*}{ BC-5.5.3 Starvation } & $47 \%$ & $\begin{array}{l}\text { A state or activity of a cell or an organism as a result } \\
\text { to the adaptation to starvation. }\end{array}$ & spot & $85 \%$ & $46 \%$ & SpoT & $31 \%$ \\
\hline & & & $d k s \mathrm{~A}$ & $12 \%$ & $3 \%$ & DksA & $8 \%$ \\
\hline \multirow[t]{2}{*}{$\begin{array}{l}\text { BC-1.1.1 Carbon } \\
\text { compounds }\end{array}$} & $46 \%$ & $\begin{array}{l}\text { The metabolic reactions by which living organisms } \\
\text { utilises carbon compounds. }\end{array}$ & lacz & $49 \%$ & $26 \%$ & LacZ & $28 \%$ \\
\hline & & & $p t s G$ & $22 \%$ & $16 \%$ & PtsG & $1 \%$ \\
\hline \multirow{3}{*}{$\begin{array}{l}\text { BC-2.3.8 } \\
\text { Ribosomal } \\
\text { proteins }\end{array}$} & $44 \%$ & $\begin{array}{l}\text { Proteins that associate to form a ribosome involved in } \\
\text { genetic information transfer in cells. }\end{array}$ & $r p / K$ & $24 \%$ & $6 \%$ & RplK & $7 \%$ \\
\hline & & & $r p s G$ & $18 \%$ & $18 \%$ & RpsG & NA \\
\hline & & & $r p s \mathrm{~L}$ & $17 \%$ & $19 \%$ & RpsL & $3 \%$ \\
\hline $\begin{array}{l}\text { BC-3.1.2.3 } \\
\text { Repressor } \\
\end{array}$ & $40 \%$ & $\begin{array}{l}\text { Any transcription regulator that prevents or } \\
\text { downregulates transcription. }\end{array}$ & fis & $41 \%$ & $6 \%$ & Fis & $9 \%$ \\
\hline $\begin{array}{l}\text { BC-3.1.2.2 } \\
\text { Activator }\end{array}$ & $32 \%$ & $\begin{array}{l}\text { Any transcription regulator that induces or } \\
\text { upregulates transcription. }\end{array}$ & fis & $45 \%$ & $6 \%$ & Fis & $9 \%$ \\
\hline
\end{tabular}

Multifun terms were assigned to annotated concepts associated with genes. A threshold of $30 \%$ of documents was considered for ontology assignment and a threshold of $10 \%$ was used to point out the genes that most contributed to such assignment.

NA: corresponds to non-annotated gene products in the corpus.

and the DksA proteins, with $28 \%$ of the assignments each, and the Elongation Factor Tu (EF-Tu), which mediates the entry of the aminoacyl tRNA into the ribosome, with $13 \%$ of the assignments.

We have paid particular attention to stress-specific ontology terms like the "response to stress" (GO: 0006950), the "response to starvation" (GO: 0042594), the "response to osmotic stress" (GO: 0006970) and the "response to DNA damage stimulus" (GO:0006974) that were assigned in almost $40 \%$ of the documents. The GO term "response to stress" was mostly assigned by the
RecA regulatory protein, the RelB transcriptional repressor and the transcription antitermination protein NusA (frequencies of assignment of $20 \%, 16 \%$ and $10 \%$, respectively). Regarding the GO term "response to starvation", SpoT enzyme detached from other contributing gene products (almost $70 \%$ of the assignments). The $\sigma^{38}$ factor and the EF-Tu protein were the main contributors to the assignment of the GO term "response to osmotic stress" (59\% and 34\% of the assignments, respectively), while the assignment of "response to DNA damage stimulus" was mainly due to the annotation of 
Table 7 GO biological processes assignments.

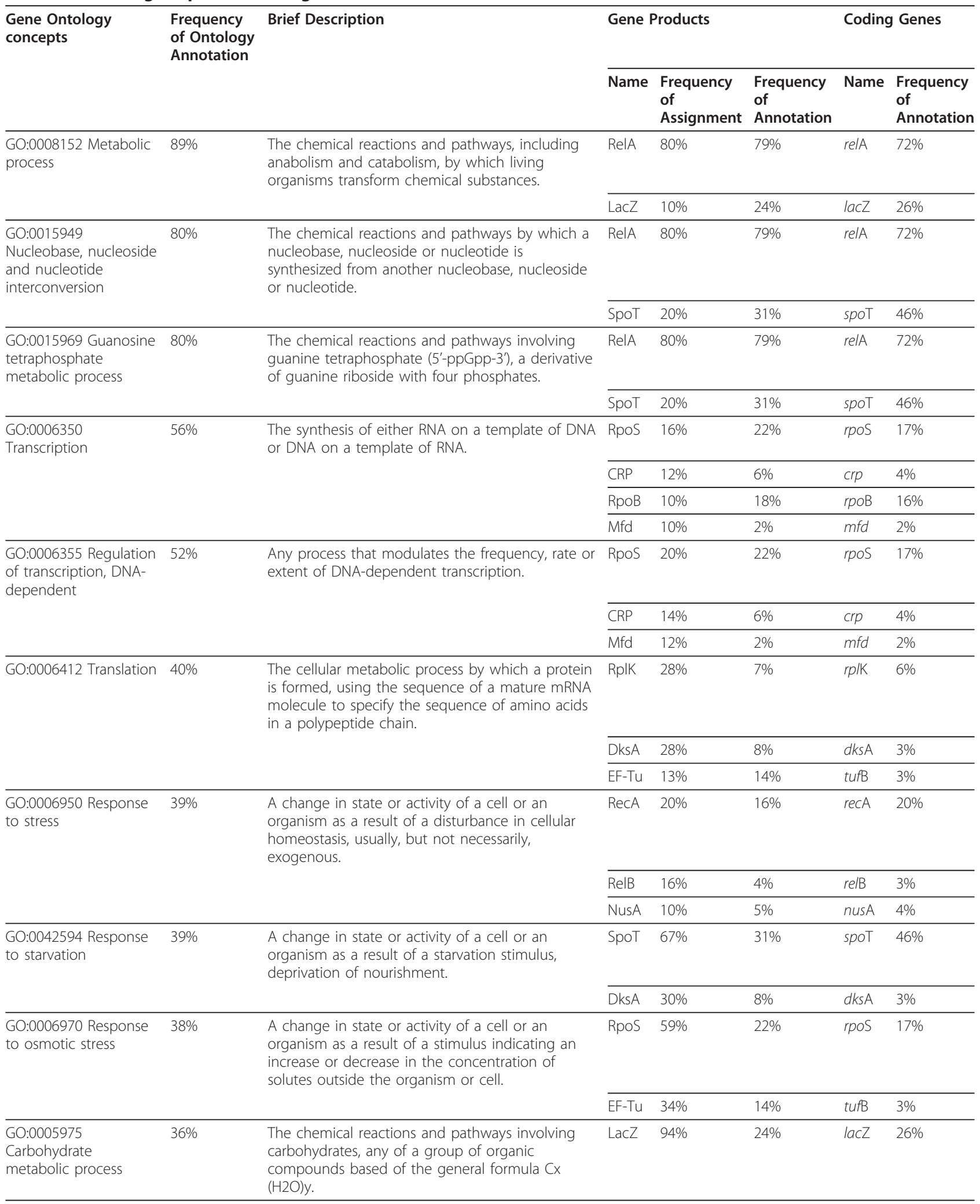


Table 7 GO biological processes assignments. (Continued)

\begin{tabular}{|c|c|c|c|c|c|c|c|}
\hline \multirow[t]{3}{*}{$\begin{array}{l}\text { GO:0006974 Response } \\
\text { to DNA damage } \\
\text { stimulus }\end{array}$} & \multirow[t]{3}{*}{$36 \%$} & \multirow[t]{3}{*}{$\begin{array}{l}\text { A change in state or activity of a cell or an } \\
\text { organism as a result of a stimulus indicating } \\
\text { damage to its DNA from environmental insults or } \\
\text { errors during metabolism. }\end{array}$} & Mfd & $28 \%$ & $2 \%$ & $m f d$ & $2 \%$ \\
\hline & & & $\operatorname{Rec} A$ & $11 \%$ & $16 \%$ & recA & $20 \%$ \\
\hline & & & $\operatorname{RecG}$ & $11 \%$ & $3 \%$ & recG & NA \\
\hline \multirow[t]{3}{*}{$\begin{array}{l}\text { GO:0006281 DNA } \\
\text { repair }\end{array}$} & $36 \%$ & $\begin{array}{l}\text { The process of restoring DNA after damage that } \\
\text { include direct reversal, base excision repair, } \\
\text { nucleotide excision repair, photoreactivation, } \\
\text { bypass, double-strand break repair pathway, and } \\
\text { mismatch repair pathway. }\end{array}$ & $\mathrm{Mfd}$ & $28 \%$ & $2 \%$ & $m f d$ & $2 \%$ \\
\hline & & & $\operatorname{Rec} A$ & $11 \%$ & $16 \%$ & recA & $20 \%$ \\
\hline & & & $\overline{\operatorname{RecG}}$ & $11 \%$ & $3 \%$ & recG & NA \\
\hline
\end{tabular}

GO terms were assigned to annotated concepts associated with gene products annotations. A threshold of $35 \%$ of documents was considered for ontology assignment and a threshold of $10 \%$ was used to point out the gene products that most contributed to such assignment.

NA: corresponds to non-annotated genes in the corpus.

proteins like Mfd, RecA and RecG (28\%, 11\% and 11\% of the assignments, respectively). The process of restoring DNA after damage, associated with the GO term "DNA repair" (GO:0006281), was also assigned by the aforementioned annotated entities.

Since results evidenced considerable assignment of stress-related processes, it was considered interesting to explore in detail the functional annotations of gene products related to $E$. coli stress responses (Table 8). A decade-by-decade analysis was performed to evaluate the extent of documents that study entities associated with these functional annotations. As shown, the response to starvation (GO:0042594) was mostly evidenced in the last decade, being assigned in almost $70 \%$ of the documents of this decade. The response to DNA damage stimulus (GO:0006974) and osmotic stress (GO:0006970) were also considerably assigned in the last decade $(50 \%$ of the documents). On the contrary, the defense response to bacterium (GO:0042742) was less assigned in the documents from the last two decades (less than $10 \%$ of the documents) and the stringent response (GO:0015968) was poorly assigned in the last decade, probably because GO only associates this biological process to the $50 \mathrm{~S}$ ribosomal subunit protein L11, which only recently has been studied in the context of this stress.

\section{Discussion}

The aim of this work was to use literature mining to complement manual curation in the revision, systematisation and interpretation of current knowledge on the stringent response of $E$. coli. Literature mining was expected to help on the identification of important biological players and their molecular functions. The controlled vocabulary extracted from the EcoCyc repository (i.e. concepts that identify biological entities like genetic components, gene products and small molecules) and ontology terms from GO, MultiFun and PSI-MI ontologies were expected to support large-scale information processing and biological contextualisation.

The application of literature mining approaches has been tested in different biological fields [3,4,6,47-50], but it is known that the quality of the information extracted has to be ensured by manual curation. At present, manual curation can extract more detailed information from literature than it is possible by mining approaches, and more accurately define the participants and their roles. However, to achieve a broad coverage, both approaches can efficiently complement each other. As such, we propose a semi-automated approach to revise, systematise and interpret the current knowledge on the stringent response of $E$. coli, based on specific controlled vocabulary for the identification of biological entities involved in this process and complemented with manual curation. Results suggested that: (i) automatic literature retrieval is able to provide documents of interest whereas controlled vocabulary from publicly available databases can support the identification of relevant entities; (ii) ontology assignments enable entity contextualisation into cellular functions and biological processes, delivering a more comprehensive and biologically meaningful scenario; and (iii) statistical analysis identifies biological entities of interest and facilitates document indexing for additional manual curation. Ultimately, the literature mining approach presented clues on entities and associations of interest and suggested which documents in the corpus should be further inspected for details on given entities or processes.

The analysis performed to the final set of annotated concepts in the corpus, evidenced the (p)ppGpp nucleotides as some of the most annotated biological entities: the ppGpp nucleotide was annotated in $75 \%$ of the documents, and the broad term (p)ppGpp exhibited the highest average of annotations per document (Table 3 ). 
Table 8 Assignment of GO concepts related to stress responses.

\begin{tabular}{|c|c|c|c|c|c|c|}
\hline \multirow[b]{2}{*}{$\begin{array}{l}\text { GO } \\
\text { Identifier }\end{array}$} & \multirow[b]{2}{*}{ GO Concept } & \multirow[b]{2}{*}{ GO Description } & \multicolumn{4}{|c|}{$\begin{array}{l}\text { Frequency of Ontology } \\
\text { Annotation }\end{array}$} \\
\hline & & & 1970 & 1980 & 1990 & 2000 \\
\hline GO:0042594 & Response to starvation & $\begin{array}{l}\text { A change in state or activity of a cell or an organism as a result of a starvation } \\
\text { stimulus, deprivation of nourishment. }\end{array}$ & - & $15 \%$ & $28 \%$ & $68 \%$ \\
\hline GO:0006974 & $\begin{array}{l}\text { Response to DNA } \\
\text { damage stimulus }\end{array}$ & $\begin{array}{l}\text { A change in state or activity of a cell or an organism as a result of a stimulus } \\
\text { indicating damage to its DNA. }\end{array}$ & $7 \%$ & $26 \%$ & $31 \%$ & $50 \%$ \\
\hline GO:0006970 & $\begin{array}{l}\text { Response to osmotic } \\
\text { stress }\end{array}$ & $\begin{array}{l}\text { A change in state or activity of a cell as a result of an increase or decrease in the } \\
\text { concentration of solutes outside the cell. }\end{array}$ & $21 \%$ & $28 \%$ & $35 \%$ & $50 \%$ \\
\hline GO:0006950 & Response to stress & $\begin{array}{l}\text { A change in state or activity of a cell or an organism as a result of a disturbance } \\
\text { in organismal or cellular homeostasis. }\end{array}$ & - & $31 \%$ & $46 \%$ & $46 \%$ \\
\hline GO:0006979 & $\begin{array}{l}\text { Response to oxidative } \\
\text { stress }\end{array}$ & $\begin{array}{l}\text { A change in state or activity of a cell or an organism as a result of oxidative } \\
\text { stress. }\end{array}$ & - & $3 \%$ & $20 \%$ & $45 \%$ \\
\hline GO:0009432 & SOS response & An error-prone process for repairing damaged microbial DNA. & - & $23 \%$ & $30 \%$ & $45 \%$ \\
\hline GO:0046677 & Response to antibiotic & $\begin{array}{l}\text { A change in state or activity of a cell or an organism as a result of an antibiotic } \\
\text { stimulus. }\end{array}$ & - & $23 \%$ & $30 \%$ & $15 \%$ \\
\hline GO:0042493 & Response to drug & $\begin{array}{l}\text { A change in state or activity of a cell or an organism as a result of a drug } \\
\text { stimulus. }\end{array}$ & - & $15 \%$ & $35 \%$ & $11 \%$ \\
\hline GO:0009266 & $\begin{array}{l}\text { Response to } \\
\text { temperature stimulus }\end{array}$ & $\begin{array}{l}\text { A change in state or activity of a cell or an organism as a result of a temperature } \\
\text { stimulus. }\end{array}$ & - & - & $9 \%$ & $11 \%$ \\
\hline GO:0042742 & $\begin{array}{l}\text { Defense response to } \\
\text { bacterium }\end{array}$ & $\begin{array}{l}\text { Reactions triggered in response to the presence of a bacterium that act to } \\
\text { protect the cell or organism. }\end{array}$ & $14 \%$ & $26 \%$ & $9 \%$ & $8 \%$ \\
\hline GO:0015968 & $\underline{\text { Stringent response }}$ & $\begin{array}{l}\text { A specific global change in the metabolism of a bacterial cell as a result of } \\
\text { starvation. }\end{array}$ & - & $13 \%$ & $7 \%$ & $6 \%$ \\
\hline GO:0009408 & Response to heat & $\begin{array}{l}\text { A change in state or activity of a cell or an organism as a result of a heat } \\
\text { stimulus. }\end{array}$ & - & $3 \%$ & $13 \%$ & $5 \%$ \\
\hline GO:0009409 & Response to cold & $\begin{array}{l}\text { A change in state or activity of a cell or an organism as a result of a cold } \\
\text { stimulus. }\end{array}$ & - & - & - & $3 \%$ \\
\hline GO:0009636 & Response to toxin & $\begin{array}{l}\text { A change in state or activity of a cell or an organism as a result of a toxin } \\
\text { stimulus. }\end{array}$ & - & - & - & $3 \%$ \\
\hline GO:0009267 & $\begin{array}{l}\text { Cellular response to } \\
\text { starvation }\end{array}$ & A change in state or activity of a cell as a result of deprivation of nourishment. & - & - & - & $1 \%$ \\
\hline GO:0046688 & $\begin{array}{l}\text { Response to copper } \\
\text { ion }\end{array}$ & $\begin{array}{l}\text { A change in state or activity of a cell or an organism as a result of a copper ion } \\
\text { stimulus. }\end{array}$ & - & - & - & $1 \%$ \\
\hline GO:0009269 & $\begin{array}{l}\text { Response to } \\
\text { desiccation }\end{array}$ & $\begin{array}{l}\text { A change in state or activity of a cell or an organism as a result of a desiccation } \\
\text { stimulus. }\end{array}$ & - & - & $4 \%$ & - \\
\hline GO:0031427 & $\begin{array}{l}\text { Response to } \\
\text { methotrexate }\end{array}$ & $\begin{array}{l}\text { A change in state or activity of a cell or an organism as a result of a } \\
\text { methotrexate stimulus. }\end{array}$ & - & - & $2 \%$ & - \\
\hline
\end{tabular}

The frequency of annotation of stress response-related concepts was estimated for documents published in the four decades analysed (from 1970 to 2009).

The extensive number of documents supporting these annotations evidenced that the role of (p)ppGpp nucleotides in the stringent response has been extensively studied. Corpus analysis disclosed that the relA gene product was also extensively studied. Indeed, over $70 \%$ of the documents addressed the activity of the relA gene and its product RelA. This enzyme was first associated to the synthesis of ppGpp in 1970 (PMID: 4315151) [51]. It is described that during amino acid deprivation the accumulation of this nucleotide increases above basal levels. Later, in 1980, the ppGpp level was found to be controlled by the SpoT enzyme via GTP hydrolysis activity (PMID: 6159345) [52]. However both the spoT gene and the SpoT enzyme have been annotated in only roughly $30 \%$ of the documents. In part, because RelA was the first enzyme discovered to be involved in the stringent response, but mostly because it is the first biological entity to respond to the amino acid starvation. Accordingly, "nucleobase, nucleoside and nucleotide interconversion" emerged as one of the most assigned ontology terms in the corpus, mainly due to the high frequency of assignment allocated to the RelA protein (80\%). Transcriptional and translational processes were also highlighted by the analysis. The acknowledgment that (p)ppGpp nucleotides manipulate gene expression, so that gene products with important roles in the starvation survival are favoured at the expense of those required for growth and proliferation, has been widely 
reported (PMID:12123445; PMID:10809680) [12,53]. In vitro studies demonstrated that (p)ppGpp bind directly to the RNAP, affecting the transcription of many genes (PMID:4553835) [54]. Also, studies hypothesised that the configuration of the RNAP is altered, decreasing the affinity of the housekeeping sigma factor (i.e. $\sigma^{70}$ ) to RNAP and thus, allowing other sigma factors to compete and influence promoter selectivity (PMID:12023304) [55]. As covered by the corpus analysis, besides RNAP (annotated in over $60 \%$ of the documents), four of the existing sigma factors in $E$. coli were also annotated: the $\sigma^{38}$ that acts as the master regulator of the general stress response (annotated in $22 \%$ of the documents); the $\sigma^{70}$ that is the primary sigma factor during exponential growth (annotated in 11\% of the documents); the $\sigma^{54}$ that controls the expression of nitrogen-related genes (annotated in 4\% of the documents); and the $\sigma^{32}$ that controls the heat shock response during log-phase growth (annotated in 3\% of the documents). Although the regulation of transcription initiation is not yet fully understood, current knowledge suggests that these four sigma factors may interact with the RNAP during stringent control.

Regarding transcription-related ontology terms, the concepts that contributed the most to these assignments were: the $\beta$ subunit of the RNAP (RpoB) to which (p) ppGpp nucleotides bind (PMID:9501189) [56]; the CRP transcriptional dual regulator that is activated in response to starvation conditions (PMID:10966109) [43]; the Fis transcriptional dual regulator, whose gene promoter is inhibited during the transcription initiation by the (p)ppGpp-bound RNAP (PMID:2209559; PMID:9973355) [33,34]; and the Mfd protein that releases the arrested RNAP-DNA complexes after (p) ppGpp nucleotides induce the transcription elongation pausing, protecting genome integrity during transient stress conditions (PMID:7968917) [57]. It is known that (p)ppGpp nucleotides not only modulate the RNAP activity, either by reducing the expression of genes like fis (which in turn modulates the expression of the crp gene) or increasing the expression of the $\sigma^{38}$ gene, but also mediate the inhibition of the RNAP replicationelongation, which afterwards requires the Mfd protein to remove the stalled RNAPs (PMID:16039593; PMID:7968917) [57,58]. Although most studies have focused on the influence of the (p)ppGpp nucleotides on the mechanisms that regulate transcription initiation activities, their regulatory effects on the elongation of DNA transcription are also important. The combined control of the DNA transcription initiation and elongation are central to a prompter cellular response to nutritional starvation [11], which has been highlighted in the present study by the presence of associated concepts in the analysis.
Similarly, (p)ppGpp also influence certain translationrelated processes. Studies showed that (p)ppGpp inhibits translation by repressing the expression of ribosomal proteins and also potentially inhibiting the activity of the particular proteins (PMID:7021151; PMID:11673421; PMID:6358217) [59-61]. Corpus analysis evidenced the annotation of ribosomal proteins, such as the $50 \mathrm{~S}$ ribosomal subunit protein L11 and the $30 \mathrm{~S}$ ribosomal subunit proteins S7 and S12, as well as the EF-Tu and the non-ribosomal DksA protein. The $50 \mathrm{~S}$ ribosomal subunit protein $\mathrm{L} 11$ has been indirectly implicated in the feedback inhibition of (p)ppGpp, because ribosomes lacking this protein are unable to stimulate the synthesis of these nucleotides (PMID:11673421; PMID:17095013) $[39,61]$. The involvement of the DksA protein in translation processes was inferred through the inspection of functional assignments. As reported (PMID:16824105) [62], DksA regulates the posttranscriptional stability of $\sigma^{38}$ factor, which increases dramatically when (p)ppGpp levels are high. Although these are the main (p)ppGpp interactions at the translational level, the impact of these nucleotides in the translation apparatus was further analysed based on the frequency of co-annotation of gene products with (p)ppGpp nucleotides that unveiled additional participants at this level. As a result, it was possible to perceive the relevance of specific translation GTPases known to be inhibited by (p)ppGpp nucleotides, namely: the Der protein that stabilises the $50 \mathrm{~S}$ ribosomal subunit and the EF-G that facilitates the translocation of the ribosome along the mRNA molecules (PMID:8531889) [36].

Apart from identifying and contextualising numerous biological participants in the stringent response, the proposed analysis (in particular, the analysis of GO functional assignments) suggested that some of the biological entities involved in other stress responses may also participate in the stringent response. Responses to starvation, DNA damage and osmotic, oxidative and SOS stresses are some examples of stress responses that were also evidenced in the analysis of the corpus (over $30 \%$ of the documents). Yet, it was striking to notice that the stringent response concept was barely assigned, probably because few biological entities are currently associated with this GO term. In fact, the $50 \mathrm{~S}$ ribosomal subunit protein L11 was the only entity in this corpus associated with that term. Nevertheless, several biological entities that interplay in different responses to stress were identified in the corpus, suggesting the overlap between stress responses. Although the relationship between these entities and the stringent response in this study is merely hypothetical, it was verified that their participation in the stringent response has been experimentally tested. For example: the link between the stringent response and the response to osmotic and 
oxidative stresses is likely to be via the involvement of the $\sigma^{38}$ factor and the EF-Tu protein; the response to DNA damage stimulus was assigned to the RecA, RecG and Mfd proteins that were verified in literature to intervene in the early dissociation of the elongation complex stalled by ppGpp [58]; and finally, the RecA regulator and the UvrABC nucleotide excision repair complex have been implicated in the DNA repair process and SOS response [63].

With the extensive list of biological players retrieved from the corpus, it was possible to recognize and investigate most of the (p)ppGpp induced cellular processes. The major participants in the stringent response were highlighted by their frequency of annotation and their representativeness in the corpus. The (p)ppGpp nucleotides and the RelA and SpoT enzymes that control (p) ppGpp basal levels, along with the RNAP, were pointed as the most significant entities in the corpus. Nonetheless, corpus analysis also revealed the involvement of entities that have been disregarded or less reported in most recent revisions $[9,11,17,24,25]$. In most cases, this is due to the fact that the reviews are not focused on the detailed description of the molecular mechanisms involved in the stringent response. They reflect the current state of knowledge, including the different levels of cellular processes that are triggered during this stress response, but do not specify which biological entities are involved in these processes. However, researchers often need to compile this information, not only for experimental purposes, but also for computational modelling or to better understand the complexity of the response. Hence, in this study, the stringent response was associated with a large set of biological entities. We have validated the role of many of those entities by inspecting directly the literature used to build the corpus, therefore also validating the usefulness of the methodology developed. However, further validation would be necessary to have a broad description of the stringent response considering the large variety of biological entities directly or indirectly affected by the (p)ppGpp within specific metabolic, transcriptional and translational processes. The systematization of information on the stringent response of $E$. coli is therefore the greatest benefit from the methodology described in this work.

Besides collecting and organizing information into functional classes, we were able to analyse the advances accomplished in the investigation of the stringent response in E. coli. Comparing the annotations of biological concepts and concepts associated with experimental techniques (based on the PSI-MI ontology terms) we followed the evolution of knowledge being reported along four decades. Technological developments have promoted the discovery of many new entities and have clarified their roles in the stringent response. At the early stage of the study of the stringent response, some traditional experimental techniques were considered decisive in the identification of the main metabolic participants (see Figure 5 and Table 5), such as the (p) ppGpp nucleotides that have been investigated since the $70 \mathrm{~s}$. Yet, in the last decades, research efforts have been focused on the newest molecular biology techniques, namely high-throughput detection methods. In particular, techniques based on array technology have addressed the rapid screening of biological entities as well as molecular interactions (PMID: 18039766; PMID: 17233676) $[64,65]$. DNA microarrays have been used to inspect the genome-wide transcriptional profiles of $E$. coli (PMID: 18039766) [64]. This technology has also provided information on transcriptional regulation, determining negatively controlled promoters (typically involved in cell growth and DNA replication) and positively controlled promoters (the amino acid biosynthesis, the transcription factors, and/or alternative sigma factor genes). Although the reconstruction of the transcriptional regulatory structure of the stringent response is far from complete, these recent advances have brought a closer view of the pleiotropic nature of the response.

Finally, results showed that it is possible to scale-up conventional manual curation coping with the everincreasing publication rate and, at the same time, provide automatic means of identifying and contextualising participants of interest. Beyond the accomplishments of the approach on this particular study, its extension to the analysis of other stress responses and/or organisms is fairly easy and interesting. However, although in the case of bacterial systems this might be simple, where naming conventions are straightforward and mostly followed by the community, in the case of other organisms, like Drosophila or plant systems, there will be more limitations. Adaptation to other scenarios implicates the compilation of sets of related documents and specialized controlled vocabularies that can be more elaborate and complex.

\section{Methods}

\section{Semi-automatic information extraction approach}

The semi-automatic information extraction approach designed to review existing literature on the stringent response of $E$. coli, integrated the following procedures: automatic document retrieval and entity recognition processes, manual curation and corpus analysis (see Figure 6).

The documents to be analysed were compiled through PubMed keyword-based searches in January 2010, using the terms ("Escherichia coli" OR "E. coli") and some variants of the term "stringent response" as reference. The process of document retrieval was limited to full-texts and it retrieved a total of 251 documents, from which 


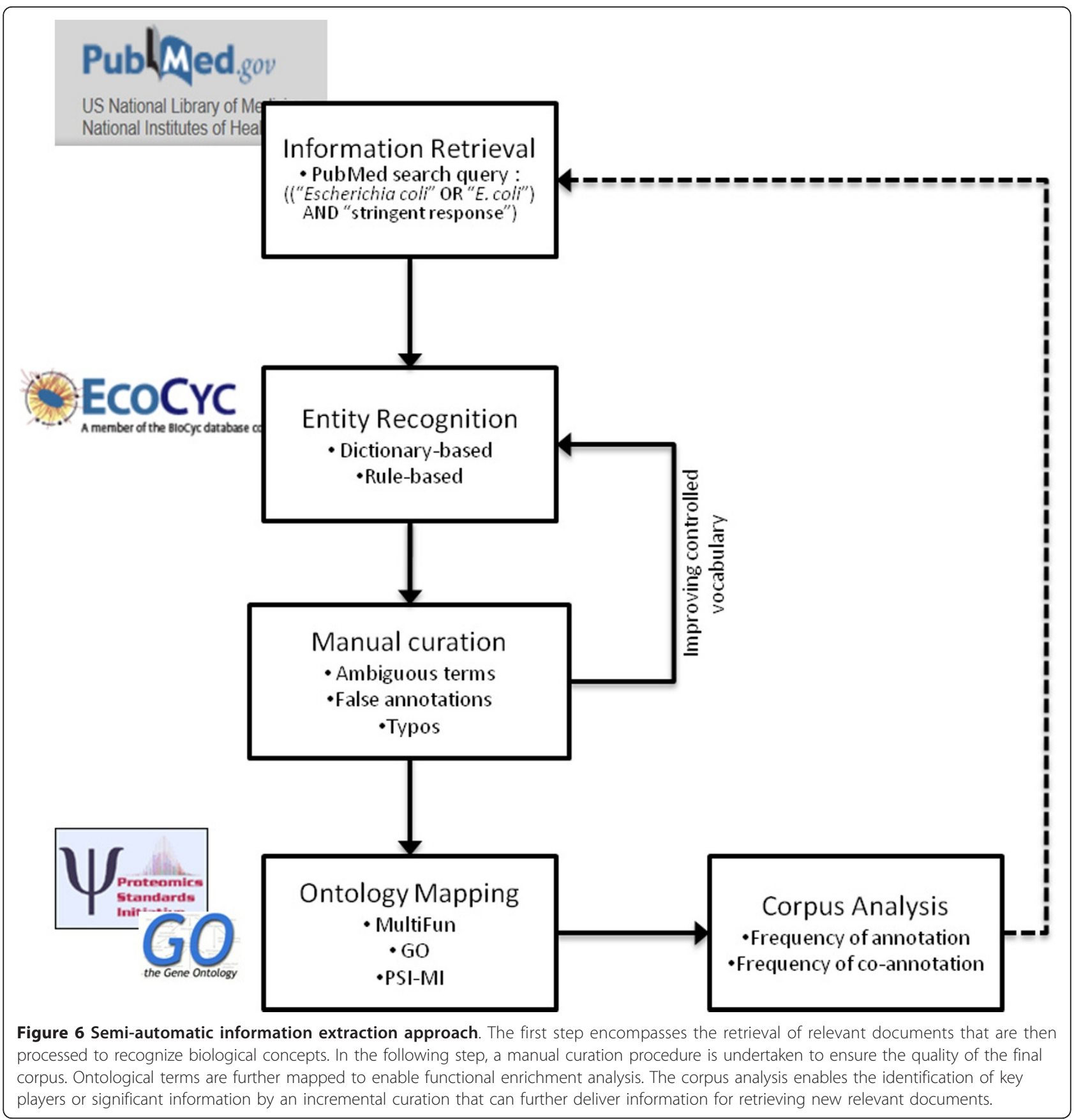

only 193 full-text documents were used due to the availability of links to full text articles in PubMed and institutional journal subscriptions. The list of documents is provided in the Additional file 1.

The automatic identification of biological concepts in those documents was done in a subtask so-called entity recognition that seeks to locate and classify concepts in texts. These concepts correspond to names or textual descriptions that are listed in a structure called controlled vocabulary that was built using information from the EcoCyc database [28], a key resource for E. coli studies, and includes biological concepts used for the recognition of genetic components (genes, RNA and DNA molecules), gene products (i.e. proteins, including transcription factors and enzymes) and small molecules (or metabolites). Additionally, a hand-crafted dictionary supported the recognition of experimental techniques and their association to PSI-MI ontology terms. For each recognized concept in documents we have estimated the number of annotations, i.e. the number of 
times that that concept appears in the body texts (including all name variants associated with that biological concept).

@Note [66], a workbench for Biomedical Text Mining supported the entity recognition process. Its regular expression module enabled the identification of genes and proteins that adhere to standard gene and protein naming conventions for $E$. coli (e.g. three lower case letters followed by a fourth letter in upper case or a term consisting of four digits preceded by character ' $b$ ' are candidates for gene names) while the dictionary-based recognition module used the terminology extracted from EcoCyc and PSI-MI ontology.

The annotated corpus was stored into XML files for further analysis. The manual curation process consisted on reviewing concept annotations, i.e., the text markups (XML tags) for recognised entities, to ensure the corpus quality and consistency. Errors of the automated recognition process such as the annotation of false entities (e. g. the word 'cap', a name variant for the CRP transcriptional factor, was wrongly annotated or words like 'release' or 'crease' were annotated as enzymes based on common enzyme suffix 'ase'), homonyms (e.g. the same term 'elongation factor $\mathrm{Tu}$ ' to designate two different polypeptides 'TufA' and 'TufB') and PDF-to-text format conversion typos (e.g. '4azaleucine' and '9galactosidase' were corrected to ' 4 -azaleucine' and ' $\beta$-galactosidase', respectively) were manually curated.

\section{Controlled vocabulary}

EcoCyc database (version 13.0, released in March 2009) provided for most of the controlled vocabulary. It supported the automatic identification of genetic components, gene products and small molecules as follows: common names and extensive name variants (synonyms) were used in the recognition of concept names in the texts; name variants were normalised by associating the corresponding database record identifier, which unequivocally identifies the concept, to the annotation; and database assignments to Gene Ontology (GO) [31] and MultiFun [30] terms enabled the mapping of annotated concepts, like gene and gene products, to the associated molecular functions and biological processes. These ontology assignments were straightforward since all entries in the EcoCyc dictionary keep the corresponding database assignments to these ontologies. Additional vocabulary was extracted from Proteomics Standards Initiative-Molecular Interactions (PSI-MI) ontology for the annotation of experimental techniques.

\section{Analysis methodology}

The number of annotations of a concept, the number of documents that contributed for those annotations and the number of documents composing the corpus constituted the baseline of the statistical metrics used in the analyses. Let $D$ be the set of documents in the corpus and $T$ be the set of annotated concepts in $D$. For every $t_{i} \in T$, the frequency, the mean, the standard deviation of annotation, and the variance-to-the mean ratio (or coefficient of dispersion) were computed as described in Table 9.

The frequency of annotated concepts, freq $q_{t i}$ (Eq.1), estimates the fraction of documents in $D$ that refers the concept $t_{i}$. In turn, the mean, $\mu_{t i}$ (Eq.2), and the standard deviation, $\sigma_{t i}$ (Eq.3), weight the number of annotations of a concept, \#annots ${ }_{t i}$, in the documents in $D$ that include that concept, $\operatorname{docs}_{t i}$, and measure the average or dispersion of the annotations, respectively. The mean indicates the representativeness of the concept in the subset docs $_{t i}$ whereas the standard deviation indicates the variability of annotations in the subset. The variance-to-mean ratio (also called index of dispersion),

Table 9 Annotation statistics used in the analysis.

\begin{tabular}{|c|c|c|}
\hline Frequency & freq $_{t_{i}}=\frac{D_{t_{i}}}{D}=\frac{\# \text { docs }_{t_{i}}}{\# \text { docs }}$ & (Eq. 1) \\
\hline Mean & mean $_{t_{i}}=\mu_{t_{i}}=\frac{\# \text { annots }_{t_{i}}}{\# \text { docs }_{t_{i}}}$ & (Eq. 2) \\
\hline Standard deviation & $s t d_{t_{i}}=\sigma_{t_{i}}=\sqrt{1 / \# \text { docs }_{t_{i}} \sum_{j=1}^{\# \text { docs }_{t_{i}}}\left(\# \text { annots }_{t_{i}, \text { doc }_{j}}-\mu_{t_{i}}\right)^{2}}$ & (Eq. 3) \\
\hline Variance-to-mean & $V M R_{t_{i}}=\frac{\sigma_{t_{i}}^{2}}{\mu_{t_{i}}}$ & (Eq. 4) \\
\hline Co-annotation & freq $_{t_{i}, t_{j}}=\frac{D_{t_{i} \cap t_{j}}}{D_{t_{i}}}=\frac{\# \text { docs }_{t_{i} \cap t_{j}}}{\# \operatorname{docs}_{t_{i}}}$ & (Eq. 5) \\
\hline
\end{tabular}


$V M R_{t i}$ (Eq.4), is a quantitative measure of the degree of clustering of concept annotations. A ratio that is greater than 1 indicates a clustered distribution, i.e., concept annotations are unevenly distributed in the subset docs $_{t i}$; less than 1 indicates an evenly dispersed distribution, i. e., concept annotations are evenly distributed in the subset docs $_{t i}$; equal to 1, a random distribution; and, equal to 0 , indicates a constant distribution, i.e., the number of concept annotations is the same in all documents that refer to the concept. Finally, the frequency of coannotation relates two different entities, assuming that entities that are often co-annotated are biologically engaged [67]. The frequency of co-annotation, freq $q_{t i, t j}$ (Eq.5), of two concepts, was estimated as the number of documents in which concepts $t_{i}$ and $t_{j}$ co-occur divided by the number of documents in which the concept $t_{i}$ appears $\left(t_{i}\right.$ is used as the reference concept). These interactions were illustrated using the Cytoscape biomolecular interaction viewer and analyser [67].

The statistics of the ontology assignments were employed in both process and functional analyses. The functions of the annotated gene products and the involved biological processes are reflected in their GO and MultiFun annotations and thus, processes and functions of interest were identified by finding statistically enriched terms (mainly by looking into the frequency of annotation). The frequency of assignment of ontology terms was estimated the as the fraction of documents where the assigning concepts were annotated. For example, if a GO term is assigned to one or more concepts that were annotated in $80 \%$ of the documents, than the frequency of that ontology term in the corpus is $80 \%$. The frequency of annotation of a given term (A) by a given concept (B) was therefore estimated based on the ratio of the number of annotations of the concept (B) by the number of times that ontology term (A) was assigned by any concept associated to that term (A). Since one concept can be associated to several ontology terms, it can be considered that the under- or overrepresentation of an ontology term can depend on the number of annotations of the assigned concepts.

Similar assessments were taken over PSI-MI assignments towards the identification of the techniques that have contributed the most to the study of the stringent response. Apart from the systematic analysis of the set of annotations in the corpus, a retrospective analysis of annotations per decade was undertaken (i.e. frequency of annotation per decade). Such analysis aimed at looking into the evolving experimental techniques that contributed to the study of the stringent response over the decades and, in particular, evaluating the impact that the technological evolution had in the identification of molecular participants.
Finally, a set of recent documents that review the literature on the subject were manually retrieved from PubMed. Their contents were evaluated in terms of annotations of genetic components, gene products and small molecules and further compared to the annotations retrieved from the corpus.

\section{Endnotes}

${ }^{1}$ The PubMed Unique Identifiers (PMIDs) indicate which documents from the corpus supported the evidences.

\section{Additional material}

Additional file 1: An Excel file with the list of documents analysed in this study.

Additional file 2: An Excel file with some details about the corpus analysis.

Additional file 3: An Excel file with the list of co-annotations between ppGpp, (p)ppGpp and ppGpp nucleotides and gene products.

Additional file 4: An Excel file comparing the extent of biological concepts described in the corpus and selected reviews.

Additional file 5: An Excel file with the list of annotations and statistical analysis of genetic components (DNA, RNA and genes).

Additional file 6: An Excel file with the list of annotations and statistical analysis of gene products (enzymes, transcriptional factors and other proteins)

Additional file 7: An Excel file with the list of annotations and statistical analysis of small molecules.

\section{Acknowledgements}

This work was partially supported by the MIT-Portugal Program in Bioengineering (MIT-Pt/BS-BB/0082/2008), the research project HeliSysBioMolecular Systems Biology Helicobacter pylori (FCT PTDC/EBB-EBI/104235/ 2008) and a PhD grant from Portuguese FCT (Fundação para a Ciência e Tecnologia) (SFRH/BD/22863/2005).

\section{Authors' contributions}

All authors participated in the preparation of the manuscript. AL and SC implemented the text mining methodology. SC performed the annotations of biological concepts in the full-text documents. AL performed the corpus analysis and ECF supervised most of the statistical analysis. IR supervised all steps of the work. All authors read and approved the final manuscript.

\section{Competing interests}

The authors declare that they have no competing interests.

Received: 14 July 2011 Accepted: 30 December 2011

Published: 30 December 2011

\section{References}

1. Garten Y, Coulet A, Altman RB: Recent progress in automatically extracting information from the pharmacogenomic literature. Pharmacogenomics 2010, 11:1467-1489.

2. Frijters $R$, van VM, Smeets $R$, van $S R$, de VJ, Alkema W: Literature mining for the discovery of hidden connections between drugs, genes and diseases. PLoS Comput Biol 2010, 6 .

3. Nobata C, Dobson PD, lqbal SA, Mendes P, Tsujii J, Kell DB, et al: Mining metabolites: extracting the yeast metabolome from the literature. Metabolomics 2011, 7:94-101. 
4. Banville DL: Mining chemical and biological information from the drug literature. Current Opinion in Drug Discovery \& Development 2009, 12:376-387.

5. Winnenburg R, Wachter T, Plake C, Doms A, Schroeder M: Facts from text: can text mining help to scale-up high-quality manual curation of gene products with ontologies. Briefings in Bioinformatics 2008, 9:466-478.

6. He X, Li YN, Khetani R, Sanders B, Lu Y, Ling X, et al: BSQA: integrated text mining using entity relation semantics extracted from biological literature of insects. Nucl Acids Res 2010, 38:W175-W181.

7. Waagmeester A, Pezik P, Coort S, Tourniaire F, Evelo C, RebholzSchuhmann D: Pathway enrichment based on text mining and its validation on carotenoid and vitamin A metabolism. Omics-A Journal of Integrative Biology 2009, 13:367-379.

8. Carneiro S, Villas-Boas SG, Ferreira EC, Rocha I: A systematic modeling approach to elucidate the triggering of the stringent response in recombinant $E$. coli systems. Advances in Intelligent and Soft Computing Springer Berlin/Heidelberg; 2011.

9. Jain V, Kumar M, Chatterji D: ppGpp: Stringent response and survival. Journal of Microbiology 2006, 44:1-10.

10. Battesti A, Bouveret E: Bacteria possessing two RelA/SpoT-like proteins have evolved a specific stringent response involving the Acyl Carrier Protein-SpoT interaction. Journal of Bacteriology 2009, 191:616-624.

11. Srivatsan A, Wang JD: Control of bacterial transcription, translation and replication by (p)ppGpp. Current Opinion in Microbiology 2008, 11:100-105.

12. Chang DE, Smalley DJ, Conway T: Gene expression profiling of Escherichia coli growth transitions: an expanded stringent response model. Molecular Microbiology 2002, 45:289-306.

13. Murray KD, Bremer H: Control of spoT-dependent ppGpp synthesis and degradation in Escherichia coli. Journal of Molecular Biology 1996, 259:41-57

14. Xiao H, Kalman M, Ikehara K, Zemel S, Glaser G, Cashel M: Residual guanosine $3^{\prime}, 5^{\prime}$-bispyrophosphate synthetic activity of relA null mutants can be eliminated by spoT null mutations. Journal of Biological Chemistry 1991, 266:5980-5990

15. Roberts JW: Promoter-specific control of E. coli RNA polymerase by ppGpp and a general transcription factor. Genes \& Development 2009, 23:143-146.

16. Chatterii $D$, Ojha AK: Revisiting the stringent response, ppGpp and starvation signaling. Current Opinion in Microbiology 2001, 4:160-165.

17. Magnusson LU, Farewell A, Nystrom T: ppGpp: a global regulator in Escherichia coli. Trends in Microbiology 2005, 13:236-242.

18. Baracchini $E$, Bremer H: Stringent and growth control of ribosomal RNA synthesis in Escherichia coli are both mediated by ppGpp. Journal of Biological Chemistry 1988, 263:2597-2602.

19. Torok I, Kari C: Accumulation of ppGpp in a relA mutant of Escherichic coli during amino acid starvation. Journal of Biological Chemistry 1980, 255:3838-3840.

20. Johnson GS, Adler CR, Collins JJ, Court D: Role of the spoT gene product and manganese ion in the metabolism of guanosine $5^{\prime}$-diphosphate $3^{\prime}$ diphosphate in Escherichia coli. Journal of Biological Chemistry 1979, 254:5483-5487.

21. Chatterji D, Fujita N, Ishihama A: The mediator for stringent control, ppGpp, binds to the beta-subunit of Escherichia coli RNA polymerase. Genes to Cells 1998, 3:279-287.

22. Artsimovitch I, Patlan V, Sekine SI, Vassylyeva MN, Hosaka T, Ochi K, et al: Structural basis for transcription regulation by alarmone ppGpp. Cell 2004, 117:299-310

23. Paul BJ, Barker MM, Ross W, Schneider DA, Webb C, Foster JW, et al: DksA: A critical component of the transcription initiation machinery that potentiates the regulation of rRNA promoters by ppGpp and the initiating NTP. Cell 2004, 118:311-322.

24. Potrykus K, Cashel M: (p)ppGpp: Still Magical? Annual Review of Microbiology 2008, 62:35-51

25. Wu J, Xie J: Magic spot: (p) ppGpp. Journal of Cellular Physiology 2009, 220:297-302.

26. Kanjee U, Gutsche I, Alexopoulos E, Zhao BY, El Bakkouri M, Thibault G, et al: Linkage between the bacterial acid stress and stringent responses: the structure of the inducible lysine decarboxylase. Embo Journal 2011, 30:931-944.

27. Traxler MF, Zacharia VM, Marquardt S, Summers SM, Nguyen HT, Stark SE, et al: Discretely calibrated regulatory loops controlled by ppGpp partition gene induction across the 'feast to famine' gradient in Escherichia coli. Molecular Microbiology 2011, 79:830-845.

28. Keseler IM, Bonavides-Martinez C, Collado-Vides J, Gama-Castro S, Gunsalus RP, Johnson DA, et al: EcoCyc: a comprehensive view of Escherichia coli biology. Nucl Acids Res 2009, 37:D464-D470.

29. Hermjakob H, Montecchi-Palazzi L, Bader G, Wojcik R, Salwinski L, Ceol A, et al: The HUPOPSI's Molecular Interaction format - a community standard for the representation of protein interaction data. Nature Biotechnology 2004, 22:177-183.

30. Serres MH, Riley M: MultiFun, a multifunctional classification scheme for Escherichia coli K-12 gene products. Microbial \& Comparative Genomics 2000, 5:205-222.

31. Ashburner M, Ball CA, Blake JA, Botstein D, Butler H, Cherry JM, et al: Gene Ontology: tool for the unification of biology. Nature Genetics 2000, 25:25-29.

32. Wren JD, Bekeredjian R, Stewart JA, Shohet RV, Garner HR: Knowledge discovery by automated identification and ranking of implicit relationships. Bioinformatics 2004, 20:389-398.

33. Walker KA, Atkins $\mathrm{CL}$, Osuna R: Functional determinants of the Escherichia coli fis promoter: roles of $-35,-10$, and transcription initiation regions in the response to stringent control and growth phase-dependent regulation. Journal of Bacteriology 1999, 181:1269-1280.

34. Ross W, Thompson JF, Newlands JT, Gourse RL: E.coli Fis protein activates ribosomal RNA transcription in vitro and in vivo. EMBO J 1990, 9:3733-3742.

35. Shiba T, Tsutsumi K, Yano H, Ihara Y, Kameda A, Tanaka K, et al: Inorganic polyphosphate and the induction of rpoS expression. Proceedings of the National Academy of Sciences of the United States of America 1997, 94:11210-11215.

36. Condon C, Squires C, Squires CL: Control of ribosomal RNA transcription in Escherichia coli. Microbiological Reviews 1995, 59:623-\&.

37. Hara A, Sy J: Guanosine 5'-triphosphate, 3'-diphosphate 5'phosphohydrolase. Purification and substrate specificity. Journal of Biological Chemistry 1983, 258:1678-1683.

38. Manganelli R: Polyphosphate and stress response in mycobacteria. Molecular Microbiology 2007, 65:258-260.

39. Jenvert RM, Schiavone LH: The flexible N-terminal domain of ribosomal protein L11 from Escherichia coli is necessary for the activation of stringent factor. Journal of Molecular Biology 2007, 365:764-772.

40. Wendrich TM, Blaha G, Wilson DN, Marahiel MA, Nierhaus KH: Dissection of the mechanism for the stringent factor RelA. Molecular Cell 2002, 10:779-788.

41. Rao NN, Liu SJ, Kornberg A: Inorganic polyphosphate in Escherichia coli: the phosphate regulon and the stringent response. Journal of Bacteriology 1998, 180:2186-2193.

42. Vinella D, Albrecht C, Cashel M, D'Ari R: Iron limitation induces SpoTdependent accumulation of ppGpp in Escherichia coli. Molecular Microbiology 2005, 56:958-970.

43. Johansson J, Balsalobre C, Wang SY, Urbonaviciene J, Jin DJ, Sonden B, et al: Nucleoid proteins stimulate stringently controlled bacterial promoters: A link between the CAMP-CRP and the (p)ppGpp regulons in Escherichia coli. Cell 2000, 102:475-485.

44. Chiaramello AE, Zyskind JW: Coupling of DNA replication to growth rate in Escherichia coli: a possible role for guanosine tetraphosphate. Journal of Bacteriology 1990, 172:2013-2019.

45. Beissbarth T, Speed TP: GOstat: find statistically overrepresented Gene Ontologies within a group of genes. Bioinformatics 2004, 20:1464-1465.

46. Martin D, Brun C, Remy E, Mouren P, Thieffry D, Jacq B: GOToolBox: functional analysis of gene datasets based on Gene Ontology. Genome Biology 2004, 5.

47. Ananiadou S, Pyysalo S, Tsujii J, Kell DB: Event extraction for systems biology by text mining the literature. Trends in Biotechnology 2010, 28:381-390.

48. Hakenberg J, Schmeier S, Kowald A, Klipp E, Leser U: Finding kinetic parameters using text mining. Omics-A Journal of Integrative Biology 2004, 8:131-152.

49. Jensen $L$, Saric J, Bork P: Literature mining for the biologist: from information retrieval to biological discovery. Nature Reviews Genetics 2006, 7:119-129. 
50. Muller HM, Kenny EE, Sternberg PW: Textpresso: An ontology-based information retrieval and extraction system for biological literature. Plos Biology 2004, 2:1984-1998.

51. Cashel M, Kalbache B: Control of ribonucleic acid synthesis in Escherichia coli 5. Characterization of a nucleotide associated with stringent response. Journal of Biological Chemistry 1970, 245:2309.

52. Lagosky PA, Chang FN: Influence of amino acid starvation on guanosine 5'-diphosphate 3'-diphosphate basal-level synthesis in Escherichia coli. Journal of Bacteriology 1980, 144:499-508.

53. Liang ST, Xu YC, Dennis P, Bremer H: mRNA composition and control of bacterial gene expression. Journal of Bacteriology 2000, 182:3037-3044.

54. Irr JD: Control of nucleotide metabolism and ribosomal ribonucleic acid synthesis during nitrogen starvation of Escherichia coli. Journal of Bacteriology 1972, 110:554-561.

55. Jishage M, Kvint K, Shingler V, Nystrom T: Regulation of or factor competition by the alarmone ppGpp. Genes \& Development 2002, 16:1260-1270.

56. Zhou YN, Jin DJ: The rpoB mutants destabilizing initiation complexes at stringently controlled promoters behave like "stringent" RNA polymerases in Escherichia coli. Proceedings of the National Academy of Sciences of the United States of America 1998, 95:2908-2913.

57. Selby CP, Sancar A: Mechanisms of transcription-repair coupling and mutation frequency decline. Microbiological Reviews 1994, 58:317-329.

58. Trautinger BW, Jaktaji RP, Rusakova E, Lloyd RG: RNA polymerase modulators and DNA repair activities resolve conflicts between DNA replication and transcription. Molecular Cell 2005, 19:247-258.

59. Pingoud A, Block W: The elongation factor Tu guanosine tetraphosphate complex. Eur J Biochem 1981, 116:631-634.

60. Pingoud A, Gast FU, Block W, Peters F: The elongation factor Tu from Escherichia coli, aminoacyl-tRNA, and guanosine tetraphosphate form a ternary complex which is bound by programmed ribosomes. J Biol Chem 1983, 258:14200-14205.

61. Yang $X$, Ishiguro $E E$ : Involvement of the $\mathrm{N}$ terminus of ribosomal protein L11 in regulation of the RelA protein of Escherichia coli. Journal of Bacteriology 2001, 183:6532-6537.

62. Nakanishi N, Abe H, Ogura Y, Hayashi T, Tashiro K, Kuhara S, et al: ppGpp with DksA controls gene expression in the locus of enterocyte effacement (LEE) pathogenicity island of enterohaemorrhagic Escherichia coli through activation of two virulence regulatory genes. Mol Microbiol 2006, 61:194-205.

63. Bichara $M$, Pinet I, Lambert LB, Fuchs RPP: RecA-mediated excision repair: a novel mechanism for repairing DNA lesions at sites of arrested DNA synthesis. Molecular Microbiology 2007, 65:218-229.

64. Durfee T, Hansen AM, Zhi H, Blattner FR, Jin DJ: Transcription profiling of the stringent response in Escherichia coli. Journal of Bacteriology 2008, 190:1084-1096.

65. Chatterii D, Ogawa $Y$, Shimada $T$, Ishihama A: The role of the omega subunit of RNA polymerase in expression of the relA gene in Escherichia coli. Fems Microbiology Letters 2007, 267:51-55.

66. Lourenco A, Carreira R, Carneiro S, Maia P, Glez-Pena D, Fdez-Riverola F, et al: @Note: a workbench for biomedical text mining. J Biomed Inform 2009, 42:710-720.

67. Shannon P, Markiel A, Ozier O, Baliga NS, Wang JT, Ramage D, et al: Cytoscape: a software environment for integrated models of biomolecular interaction networks. Genome Research 2003, 13:2498-2504.

68. Jones PG, Cashel M, Glaser G, Neidhardt FC: Function of a relaxed-like state following temperature downshifts in Escherichia coli. Journal of Bacteriology 1992, 174:3903-3914.

69. Mogk A, Deuerling E, Vorderwulbecke S, Vierling E, Bukau B: Small heat shock proteins, ClpB and the DnaK system form a functional triade in reversing protein aggregation. Molecular Microbiology 2003, 50:585-595.

70. Shinagawa H, Makino K, Amemura M, Kimura S, Iwasaki H, Nakata A: Structure and regulation of the Escherichia coli ruv operon involved in DNA repair and recombination. Journal of Bacteriology 1988, 170:4322-4329.

71. Sabnis NA, Yang $H$, Romeo T: Pleiotropic regulation of central carbohydrate metabolism in Escherichia coli via the gene csrA. Journal of Biological Chemistry 1995, 270:29096-29104.

72. Pernestig AK, Melefors O, Georgellis D: Identification of UvrY as the cognate response regulator for the BarA sensor kinase in Escherichia coli. Journal of Biological Chemistry 2001, 276:225-231.
73. Dubey AK, Baker CS, Suzuki K, Jones AD, Pandit P, Romeo T, et al: CsrA regulates translation of the Escherichia coli carbon starvation gene, cst $\mathrm{A}$, by blocking ribosome access to the cstA transcript. Journal of Bacteriology 2003, 185:4450-4460

74. Yamanaka K, Inouye M: Growth-phase-dependent expression of cspD, encoding a member of the CspA family in Escherichia coli. Journal of Bacteriology 1997, 179:5126-5130.

75. Podkovyrov SM, Larson TJ: Identification of promoter and stringent regulation of transcription of the $f a b H, f a b D$ and $f a b G$ genes encoding fatty acid biosynthetic enzymes of Escherichia coli. Nucl Acids Res 1996, 24:1747-1752.

76. Peterson CN, Mandel MJ, Silhavy TJ: Escherichia coli starvation diets: essential nutrients weigh in distinctly. Journal of Bacteriology 2005, 187:7549-7553.

77. Gong L, Takayama K, Kjelleberg S: Role of spoT-dependent ppGpp accumulation in the survival of light-exposed starved bacteria. Microbiology 2002, 148:559-570

78. Almiron $M$, Link AJ, Furlong D, Kolter R: A novel DNA-binding protein with regulatory and protective roles in starved Escherichia coli. Genes Dev 1992, 6:2646-2654.

79. Aizenman E, Engelberg-Kulka H, Glaser G: An Escherichia coli chromosomal "addiction module" regulated by guanosine 3',5'-bispyrophosphate: a model for programmed bacterial cell death. Proceedings of the National Academy of Sciences of the United States of America 1996, 93:6059-6063.

80. Gross M, Marianovsky I, Glaser G: MazG - a regulator of programmed cell death in Escherichia coli. Mol Microbiol 2006, 59:590-601.

doi:10.1186/2042-5783-1-14

Cite this article as: Carneiro et al:. Stringent response of Escherichia coli: revisiting the bibliome using literature mining. Microbial Informatics and Experimentation 2011 1:14.

\section{Submit your next manuscript to BioMed Central and take full advantage of:}

- Convenient online submission

- Thorough peer review

- No space constraints or color figure charges

- Immediate publication on acceptance

- Inclusion in PubMed, CAS, Scopus and Google Scholar

- Research which is freely available for redistribution

Submit your manuscript at www.biomedcentral.com/submit
C Biomed Central 